\title{
Stabilization Policy and Private Economic Behavior
}

WILL THE initiation of active macroeconomic stabilization policies change the behavior of the private sector? If so, what will these changes be? And what are their implications for the design and effectiveness of stabilization policy?

I will use two ways of searching for answers to these questions. The first is empirical. It involves looking at recent history and trying to discern relevant signs or patterns. The aim is to describe how the private sector has responded to cyclical fluctuations and how these responses have changed over time.

The second approach is analytical. It explores consequences for the design and effectiveness of policy that stem from the assumption that private economic agents anticipate countercyclical policy actions. Why should this be a helpful exercise? After all, as many have suggested and as the empirical section of this paper generally shows, no clear-cut rules can describe postwar macroeconomic policy. Nor is it clear that all private economic agents make unbiased predictions of economic variables and incorporate expectations about policy actions into their predictions. Nevertheless, an answer to the "what if" question is helpful. If the effectiveness of policy actions depends upon the ability of policymakers to surprise the private sector, there is a legitimate worry about a decline in the impact of policy with its repeated use. If, on the other hand, the effectiveness of

Note: I would like to thank participants in the Brookings panel and several colleagues at Yale for helpful comments. David S. Coppock and Robert Lurie provided excellent research assistance. Financial support was provided by the National Science Foundation. 
policy is enhanced by rational anticipatory behavior in the private sector, this worry is groundless and there is even a case for the dissemination of information about the aims and design of stabilization policy.

Whether people anticipate policy and whether this matters are widely debated questions at present. ${ }^{1}$ The underlying issue is whether the sum of individual actions serves to maximize welfare in the absence of coordinating actions from a central authority. If the only cause of the business cycle is surprise events and if the private economy can itself act quickly to restore full-employment equilibrium following any initial shock, then policy actions are probably at best unnecessary and at worst undesirable. ${ }^{2}$ In such a context, it is natural to think of the private sector acting to minimize the impact of policy, to counteract its intent, just as most people minimize their liability for income taxes.

Post-Keynesian models often cite random shocks as the initiators of the business cycle, but stress the inability of the private economy to restore full employment in the short run. In this context it is more natural to think of the private sector welcoming the impact of policy ${ }^{3}$ and perhaps even reinforcing its effects. Since the view of the business cycle taken in this paper is in the post-Keynesian tradition, its conclusions, not surprisingly, differ from those of models with more classical assumptions.

The rationality of expectations is the aspect of recent classical models that has received the most attention. But other assumptions are more crucial to the findings about policy, and they are much harder to accept.

1. Robert E. Lucas, Jr., "Econometric Policy Evaluation: A Critique," in Karl Brunner and Allan H. Meltzer, eds., The Phillips Curve and Labor Markets, Carnegie-Rochester Conference Series on Public Policy, vol. 1 (Amsterdam: NorthHolland, 1976), pp. 19-46; Thomas J. Sargent, "A Classical Macroeconometric Model for the United States," Journal of Political Economy, vol. 84 (April 1976), pp. 207-37; William Fellner, Towards a Reconstruction of Macroeconomics (American Enterprise Institute, 1976); Edmund S. Phelps and John B. Taylor, "Stabilizing Powers of Monetary Policy under Rational Expectations," Journal of Political Economy, vol. 85 (February 1977), pp. 163-90; Stanley Fischer, "Long-Term Contracts, Rational Expectations, and the Optimal Money Supply Rule," Journal of Political Economy, ibid., pp. 191-205; Franco Modigliani, "The Monetarist Controversy or, Should We Forsake Stabilization Policies?" American Economic Review, vol. 67 (March 1977), pp. 1-19; Ray C. Fair, "A Criticism of One Class of Macroeconomic Models with Rational Expectations" (August 1977; processed).

2. For this result to hold it must also be true that any systematic serial correlation of random shocks be correctly anticipated and allowed for.

3. This point is made by Arthur M. Okun, "Fiscal-Monetary Activism: Some Analytical Issues," BPEA, 1:1972, pp. 123-63. 
In particular, flexibility of prices is required in order that equilibrium be restored quickly after some disturbance. To the extent that stickiness of prices or wages is caused by illusion or arbitrariness, rational expectations should rule it out. However, recent theories of price and wage setting and long-standing theories of imperfect markets have provided at least the beginnings of a reconciliation of rationality and stickiness. The persistence of price and wage inflation through recessionary periods is a fact to which theory must adapt.

The plan of the paper is as follows. First, there is a brief comparison of the periods before and after World War II that suggests that the initiation of policy has made a difference, even if the Great Depression is excluded. The emphasis then shifts to the postwar period, when, according to the argument here, important changes have occurred both in policy and in people's perception of it. Econometric evidence is then presented that looks consistent with the hypothesis that these changes in the policy environment have induced changes in private behavior.

The empirical evidence may be suggestive but it is not conclusive. Some analytical issues of the impact of anticipated policy are explored with a simple theoretical model.

\section{The Climate of Greater Stability}

The Federal Deposit Insurance Corporation is a remarkable institution. Prior to its existence bank failures and runs on banks were very common. Since it came into being it has rarely had to pay out. Other things have not been equal, of course, but the fact that deposits are insured changes the behavior of depositors in a way that induces greater stability in the banking system. Fears of a run on the bank can become self-fulfilling as depositors scramble to withdraw funds. Even if an individual knows for a fact that a bank is basically sound, he is not being irrational to hurry to the teller's window for his money once the rush starts.

The analogy to the existence of stabilization policy is not exact, but it has some validity. If everyone believes that major depression and runaway inflation can be controlled, these events become less likely. A recession will not induce the same panicky cutbacks in investment or employment; an inflation will not induce the same flight from money and financial assets.

Deposit insurance chops off the tails of the distribution, but stabiliza- 


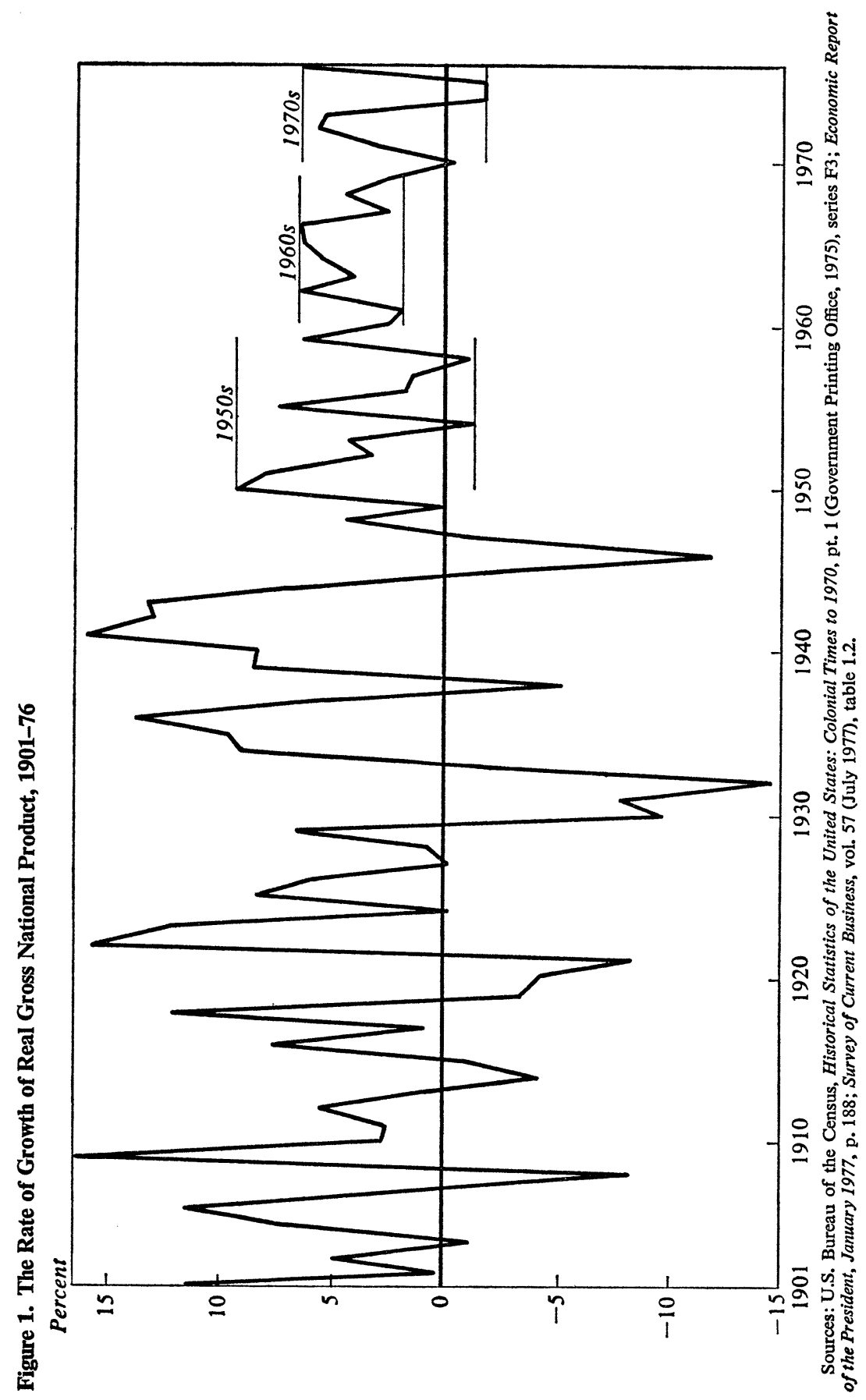


tion policy attempts to go beyond this-to smooth output fluctuations. The more stable the economic environment the fewer the economic resources that have to be devoted to contingency planning, to adjusting schedules, and to designing for flexibility. For example, a production process that may be the least-cost one when operations are near capacity may be a very high-cost one when capacity is underutilized. Greater stability of demand then permits the use of the least-cost process. Furthermore, when private individuals are risk averse, stabilization yields a tremendous gain. If the overall economic environment can be made less uncertain, a general gain in welfare will result.

Is there any sign that stabilization policy has actually produced greater stability? The Employment Act of 1946 marked an important turning point. It expressed the political will to avoid recession or depression, and the Keynesian revolution in macroeconomic theory held that stabilization policy could be the instrument of that will. Figure 1 simply plots the rate of growth of real gross national product for the period 1901-76 while table 1 gives some means and standard deviations for the GNP gap, unemployment, and inflation. The broad outlines of the story are familiar. But the change in the amplitude of cyclical fluctuations is surprisingly dramatic. The impact of the 1946 act is not seen immediately, but from about 1948 on the change is clear from figure 1. The figure also reveals that the magnitude of the swings in the Great Depression were not so unusual as one might have thought. It is the sequence of three successive sharp downturns that marks off this period. Serious instability is evidenced even as late as 1946 itself, when the abrupt reduction in war-related expenditure resulted in a 12 percent decline in real GNP.

Table 1 shows that the standard deviation of GNP around its trend and the standard deviation of the unemployment rate are both higher in all early periods than they were in all later ones. The differences are statistically significant under the assumption (admittedly rather dangerous) that each annual observation is an independent random drawing. ${ }^{4}$ Some of the difference may be attributable to greater errors in the data for the earlier periods, but the general picture is the same even without relying on such data. For example, Schumpeter gives evidence of sharp booms and slumps

4. Tests were performed on whether the variances of the GNP-gap variable across periods were significantly different from each other. The variances for 1920-41 and 1900-45 were significantly greater than all the postwar variances at the 1 percent level. The variance for 1900-16 and 1920-29 was significantly greater than the 1948-61 variance at the 5 percent level, the remainder at the 1 percent level. 
Table 1. Variability of GNP, the Rate of Unemployment, and the Rate of Inflation, Selected Periods before and after 1946

\begin{tabular}{|c|c|c|c|c|c|}
\hline \multirow[b]{2}{*}{ Period } & \multirow{2}{*}{$\begin{array}{l}\text { GNP gap, } \\
\text { standard } \\
\text { deviation }\end{array}$} & \multicolumn{2}{|c|}{ Unemployment rate } & \multicolumn{2}{|c|}{ Inflation rate ${ }^{\mathbf{b}}$} \\
\hline & & Mean & $\begin{array}{l}\text { Standard } \\
\text { deviation }\end{array}$ & Mean & $\begin{array}{l}\text { Standard } \\
\text { deviation }\end{array}$ \\
\hline \multicolumn{6}{|l|}{ Before 1946} \\
\hline $1900-16,1920-29$ & 6.21 & 4.95 & 2.23 & 1.06 & 4.56 \\
\hline $1920-41$ & 12.99 & 11.52 & 7.59 & -0.57 & 5.74 \\
\hline $1900-45$ & 13.58 & 7.77 & 6.51 & 1.86 & 6.11 \\
\hline \multicolumn{6}{|l|}{ After 1946} \\
\hline $1948-61$ & 3.38 & 4.79 & 1.29 & 2.14 & 2.68 \\
\hline $1962-73$ & 2.46 & 4.74 & 0.88 & 3.37 & 1.84 \\
\hline $1966-76$ & 2.26 & 5.25 & 1.66 & 5.54 & 2.56 \\
\hline $1946-76$ & 3.56 & 4.95 & 1.34 & 3.84 & 3.60 \\
\hline
\end{tabular}

Sources: U.S. Bureau of the Census, Historical Statistics of the United States: Colonial Times to 1970, pt. 1 (Government Printing Office, 1975), series F3, D9, D87, E135; Economic Report of the President, January 1977, pp. 188, 221, 242; Survey of Current Business, vol. 57 (July 1977), p. S-8 and table 1.2.

a. The GNP gap is defined as (GNP - trend GNP)/trend GNP, where trend GNP is computed from fitting a logarithmic time trend to GNP over the specific subperiod. Values are for real GNP.

b. The inflation rate is measured by the consumer price index.

going back all through the nineteenth century. ${ }^{5}$ These swings appeared to last for several years and were not perceived as uncorrelated movements around a full-employment equilibrium.

The rate of inflation, as measured by the consumer price index, has also varied less in the postwar period. But the average rate of inflation has been higher, especially in the years 1966-76. Price stability has not been achieved.

Table 1 and figure 1 give only crude evidence. But for what it is worth, it is consistent with the view that the Keynesian revolution taught us how to stabilize the real variables of output and unemployment, but not how to combine low and stable unemployment with price stability. The same figures present a challenge to anyone trying to make the case that policy can and should control the price level, but has no influence on real variables. $^{6}$

It is important to make a full accounting of the changes that took place

5. Joseph A. Schumpeter, Business Cycles: A Theoretical, Historical, and Statistical Analysis of the Capitalist Process, vols. 1 and 2 (McGraw-Hill, 1939).

6. Note also that despite the declining importance of self-employment and the presence of unemployment insurance, minimum wages, and the baby boom, the average unemployment rate is the same for $1946-76$ as it was in the nonwar, nondepression periods $1900-16$ and 1920-29. 
in the way economic policy is made. Before World War II it was thought that raising taxes to balance the budget in a recession and allowing "unsound" banks to fail were both neutral or laissez-faire policies. Understanding how to avoid destabilizing the economy and enacting social programs that automatically stabilized it were both at least as important as was learning how to use discretionary policy. ${ }^{7}$

Several previous writers have recognized the greater stability of the postwar period, and some have gone on to suggest that not only has policy changed the path of real output, but also private behavior has been affected. Specifically, a confidence effect has been suggested. For example, William Nordhaus has argued that a decline in the rate of return on capital is consistent with a decline in the risk premium for capital investments. ${ }^{8}$ In a detailed examination of the financial behavior of corporations, $\mathrm{Hy}-$ man Minsky found that shifts in the portfolio and leverage positions of corporations in the postwar period reflect a belief that depression conditions will not recur. He concludes this because many corporations would be vulnerable to bankruptcy if faced by a new depression. ${ }^{9}$

An important question, examined further below, is the extent to which the hypothesized confidence effect has come about directly. Perhaps people understand fully the principles of policymaking and predict how it will be used, or, alternatively, they may have little understanding of policy, but simply find that the economy is more stable and change their behavior as a result. These alternatives have very different implications in some situations. ${ }^{10}$

Finally, two qualifications are in order. First, the postwar period has not been uniformly stable. The erosion of confidence during 1973-75 and

7. In particular, the argument that the stability after World War II has resulted in part simply from the large size of the government sector, while not wrong, is surely deceptive. For example, the government can simply purchase an army when it needs it and send it home when it does not; but doing so without any offsetting action will cause a problem-witness 1946. A large but volatile government sector may be worse than a small government sector.

8. William D. Nordhaus, "The Falling Share of Profits," BPEA, 1:1974, pp. 169208.

9. Hyman P. Minsky, "Private Sector Asset Management and the Effectiveness of Monetary Policy: Theory and Practice," Journal of Finance, vol. 24 (May 1969), pp. 223-38.

10. For example, Edmund S. Phelps' idea of using policy announcements to have a direct impact on inflation depends upon the direct link between policy and behavior. See "Disinflation without Recession: Adaptive Guideposts and Monetary Policy" (Columbia University, October 1977; processed). 
other changes are discussed extensively in the following analysis. Second, cyclical instability is by no means the only form of serious uncertainty for firms; shifts in comparative advantage are another. The point remains that one major source of instability has been ameliorated.

\section{Policy and Perception of Policy after World War II}

A brief discussion of the changing policy environment and the changing perceptions of policy since World War II may shed a little light on whether policy has a direct effect on behavior or only an indirect effect, through its impact on demand and output. It will also provide a background against which the econometric evidence of the next section can be interpreted. The econometric evidence will not compare the prewar and postwar periods. The data for the prewar period are weak, and, in any case, the postwar years provide sufficient variability both in policymaking and in perceptions of policy. The evidence, therefore, looks for changes within the latter period. Consider now the changing perceptions of policy, provided primarily by a review of the business press. ${ }^{11}$ Three phases will be distinguished. The first is from 1948 until the beginning of the sixties (leaving aside the immediate postwar years); the second from the beginning of the sixties through 1971; the third since 1971.

During the first phase policymakers had committed themselves to an attempt to mitigate the effects of the business cycle, but they were not entirely confident of whether or how this could be done. Policy actions were viewed mainly as leaning against the wind rather than giving full control over the cycle. Moreover, there were important constraints on policy: the Federal Reserve felt an obligation to maintain stability in the bond market and to assist the financing of federal debt; and fiscal policy, then even more than now, was heavily constrained by the desire to balance the budget.

Even as early as 1946, the business community showed considerable awareness of the aims of stabilization policy and the mechanisms by which it might work. In 1946, Business Week discussed in detail the Employment Act and the formation of the Council of Economic Advisers. On

11. Two Yale undergraduates, John Friedman and Kathy Sheehan, surveyed Business Week and the Commercial and Financial Chronicle for me. Their reports were supplemented by some reviewing of my own. 
Keynes' death, reviews of his theories cited them as demonstrations that man had learned to control his economic destiny. However, the general tone throughout this period was very cautious, especially in the more conservative publications. There was great fear of budget deficits, a mistrust of government intervention of any kind, a fear of letting inflation get out of hand, and a general skepticism about whether policy really could do anything to help smooth the cycle. The independence of the Federal Reserve was viewed as extremely desirable, largely because its governors were trusted to resist the inflationary printing press more than was the Treasury, which was viewed as too political.

The second phase of the postwar period covered the activist and generally expansionist policies followed during the 1960s. In its March 17, 1962, issue, Business Week commented: "John F. Kennedy is beginning to show what kind of President he intends to be.... He will be a President who intervenes overtly and systematically in areas of the U.S. economy that, in theory at least, always operated on their own. . . . All modern Presidents have intervened in the economy to some extent. The distinctive thing about the Kennedy brand of intervention is that it has been accepted as a conscious and consistent policy." The rapid growth with low inflation in the mid-1960s was to a considerable extent attributed to the activist policy measures. Even the skeptics, who had been given to frequent complaints about the "Keynesian nonsense," began to speak of a consensus concerning the benefits of using fiscal and monetary policies to control the economy. ${ }^{12}$

The third phase, beginning in 1971 , is the hardest one to characterize. Clearly, there has been a change in the climate since the 1960s in terms of both policymaking itself and the reactions to it. Policymakers have displayed much more concern with inflation, and the confidence of businessmen in the desirability of policy has waned. But expectations have not returned to what they were in the old days. In the 1970s, there remains a view that the path of the economy is governed by an interaction between the endogenous economy and policy actions, and that policy has tremen-

12. This was true, for example, of the normally skeptical editorials in the Commercial and Financial Chronicle. Herbert Stein commented on the consensus within the economics profession for a fiscal stimulus: "If [Kennedy] had chosen six American economists at random the odds were high that he would have obtained five with the ideas on fiscal policy which his advisers actually had, because those ideas were shared by almost all economists in 1960." See The Fiscal Revolution in America (University of Chicago Press, 1969), p. 380. 
dous importance. "The fundamental cause of recession and high unemployment is not ... history, but inflation. Inflation can cause recession in two basic ways. The first (and most common) has to do with government actions, while the second ... [is that] if inflation is virulent enough, it will cause recession directly, by draining purchasing power enough to retard consumption significantly." 13

The current decade is a complex time for policymaking, and a simple story will not suffice to explain it. The main theme has been the fight against inflation, by mild recession, by controls, and finally by tolerating a very high level of unemployment. The business press reveals an almost obsessive concern with predicting policy. Nevertheless, they made some wrong guesses. When sales began to fall in 1973-74, the business community did not quite believe policymakers would sit on their hands and allow a deep recession. Once it became clear that they would, however, the consensus developed (correctly) that the recovery would be slow. The fear of inflation would (and did) restrain any powerful measures toward stimulus.

The most persistent irrationality observed concerns the budget deficit. Since no serious school of economic thought argues a direct link between inflation and the deficit, it is hard to understand why this myth persists. ${ }^{14}$

Any review of this kind is necessarily subjective. But the division into three reasonably distinct phases seems justified. The forties and fifties were a period of learning about what policy can do-for both the private sector and the policymakers. During the sixties people had considerable confidence in stabilization policy and a belief that it was a major factor in determining output. Policy shifted emphasis in the seventies, and a good deal of enthusiasm was lost, but it was still seen as a major factor in determining output.

Throughout the period there has been tremendous interest in understanding and predicting policy, as evidenced by the business press. By the 1970s this interest was at a very high level indeed. However, exposure does not imply understanding. The business sector may or may not be able

13. Irwin L. Kellner, "Quarterly Business Conditions Analysis," Business Report (Manufacturers Hanover Trust, June 1977). (Emphasis added.)

14. Periods of high budget deficits are sometimes also periods of high money growth, it is true. However, the myth of a direct influence, even of deficits financed without money creation, is very strong, 
to predict policy actions very well and it may or may not understand policy implications very well. It is certainly trying hard to do both.

The basic facts underlying the evolution of expectations described above have already been given. With the experience of 1901-46 behind them, few firms could have been expected to believe immediately that the postwar cycles would be so different. It took experience to demonstrate the change. Even if policy had been applied in a perfectly uniform way from 1948 to 1976 and even if this had resulted in a path for the economy that looked much the same throughout the period, a shift in private behavior would still have been expected, at least between, say, the period 1948-61 and later years.

Of course, in practice, policy has not been at all uniform and figure 1 supports the breakdown into three phases. The swings in the fifties were perceptibly sharper than any in the remarkably stable sixties. The two successive sharp declines of 1974 and 1975 stand out in the third phase.

I realize that some will feel that a link is missing in this discussion. Nothing has been said about the growth rate of the money supply or the tax cut of 1964 or other fiscal policy. I have commented on the aims of policy, on what people thought about policy, and I have looked at what happened to GNP and unemployment. Linking policy goals, policy actions, and actual economic events is a major task, properly the task of another paper. Indeed, it has been the task of several papers.

The work of George Perry is particularly relevant. ${ }^{15}$ Perry shows that policy was generally acting to restrain growth in the quarters leading up to a peak and acting to stimulate growth in the quarters following a trough. This is consistent with the aim of damping down output swings in both directions. However, fiscal policy was expansionary going up to the peak of 1953:2 and contractionary around the trough of 1954:2, which is in particular contrast to its stimulative effect after subsequent troughs. This finding is consistent with the view that fiscal policy was not yet on track in the mid-fifties.

The observation that policy in general, or monetary policy in particular, has caused postwar recessions does not necessarily conflict with the hy-

15. George L. Perry, "Stabilization Policy and Inflation," in Henry Owen and Charles L. Schultze, eds., Setting National Priorities: The Next Ten Years (Brookings Institution, 1976), pp. 271-321, especially tables 7-1 and 7-4. Other references are given in that paper. 
pothesis of this paper. One would expect to see evidence of concern about inflationary pressure, especially on the part of the Federal Reserve.

This section presents some evidence suggesting that a given fluctuation in output or sales has induced different responses in three important decision variables of firms-employment, inventories, and investmentdepending upon the postwar phase in which it occurred.

\section{Changing Responses to the Cycle}

Two points should be stressed from the start. First, although in most cases the estimated equations are based upon past work in fitting equations, the aim is not at all to pick the best econometric equation and then test for shifting parameters. The best-fitting econometric equations will often include explicit expectational variables, like surveys of sales forecasts, or implicit proxies, like the stock market, that contain expectational information. If the mechanism by which expectations are formed has changed, then the change is wholly or partly caught in these variables. One of the purposes of the evidence presented here is to test whether cyclical fluctuations, often output changes, have continued to induce the same responses in employment or investment or other variables over the postwar period.

Second, if hard evidence on expectations were available, one could test for changes in the relationship between expectations and the cycle. Unfortunately, it is not. Instead, the more direct approach described above is taken, and it cannot rule out the possibility that "other factors" may have caused shifts in responsiveness. Hence, no claim is made that the evidence given here proves that private economic behavior has changed as a result of policymaking. But this limitation is always true of econometric evidence: significant coefficients do not prove causality. In the equations given below, however, the range of other interpretations may be wider than usual. At most, I will claim that there may be traces of milk on the cat's whiskers.

What signs of the changes in the expectational environment would be expected? If policy has smoothed cyclical fluctuations, increased the probability of a return to full employment, and reduced the probability of extreme outcomes, firms will view a given short-run change in output as less likely to persist or intensify. The adjustment of employment and investment to short-run movements in output will, therefore, be less com- 
plete. Firms will be more willing to take a long view. Despite a downturn, they will continue to invest; and they will tend more to hold onto their workers. Similarly, they will react less to upturns. Output changes will still have an impact, but it will become less pronounced.

\section{THE RESPONSE OF EMPLOYMENT}

When an individual firm is struck by a downturn or an upturn in demand, the way it reacts depends importantly on whether the change is expected to continue, intensify, or be reversed in the near future. The firm can react with some combination of three actions: laying off or hiring workers, varying hours of work per worker, and increasing or decreasing inventories. Each element of the decision costs something. Hiring, firing, and training costs are incurred directly by firms when employment is varied. Income uncertainty and the disutility of overtime are costs faced by workers when either employment or hours are varied. They become costs for the firm to the extent that firms must compensate workers for them with higher base wage rates or overtime premiums.

Holding inventories allows a gap between production and sales, but at the cost of interest expenses and storage charges. Firms may also hold excess labor rather than piling up unsold inventories. This labor hoarding may take the form of payment for more hours than employees actually provide or of requiring less intense effort from employees during downturns.

Table 2 shows how the relationship between production and employment has shifted in the postwar period. The logarithm of employment is regressed on a time trend and the logarithm of current and lagged values of output. The data used are quarterly for the private nonfarm economy and the equations are run over various periods between 1948 and 1976. The response of employment to output is strikingly different during the period 1948-61 than it is in later periods. The size of the response is different and, to a lesser extent, so is the speed. Statistical tests reveal that the relationship between employment and output has shifted significantly. ${ }^{16}$ In the 1948-61 period, the estimates indicate, a sustained fall in output equal to a 5 percent rate induced a 2.42 percent decline in employment in the same quarter and a 5.35 percent decline after five quarters. The parameters for the 1962-71 period indicate that the same decline in out-

16. The hypothesis that the parameters remain the same over either 1948-71 or $1948-76$ is rejected decisively at the 1 percent level in both cases. 


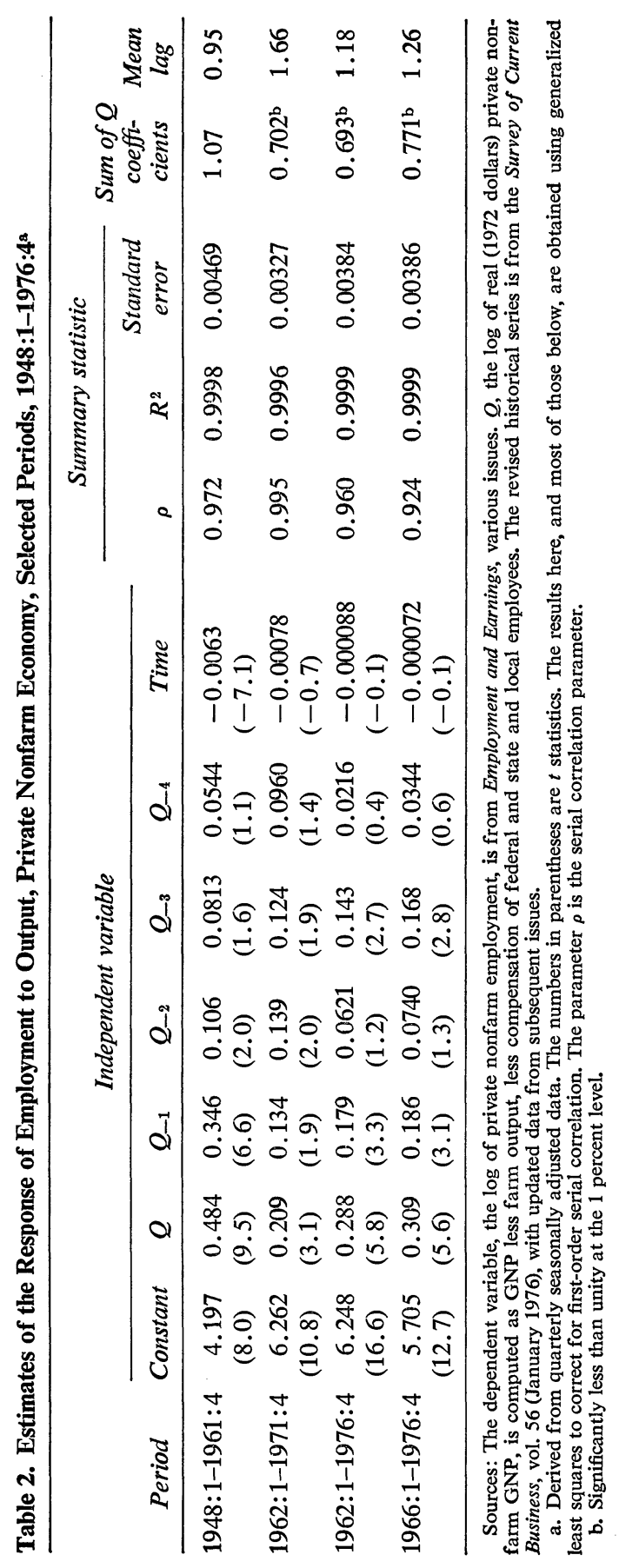


put induced only a 1.05 percent decline in employment in the same quarter. After five quarters the drop is only 3.50 percent.

The equation estimated over 1948-61 shows employment changes in proportion to output, allowing for a year to adjust; over that interval, there is even a slight trace of decreasing returns to labor. The coefficient on time indicates a productivity trend of about $2 \frac{1}{2}$ percent a year. Most of the adjustment of employment occurs in the current and the next quarter. The same equation estimated after 1961 looks very different. Both the long-run elasticity and the productivity trend are much smaller and the constant is larger.

These results, therefore, support the hypothesis of less complete adjustment to short-run changes in output after 1962. If firms begin to extrapolate output forward using a trend growth rate-that is, if they take a long view-the apparent productivity time trend will tend to drop. Again the results support this view.

Using the private nonfarm economy seemed the most natural approach. It could be argued, however, that the decline in the fraction of production and nonsupervisory workers in the sector (from 87.9 percent in 1948 to 82.6 percent in 1974), along with changes in the sectoral mix of employment, could be causing the results shown. To check this view the equations of table 2 were run for production workers in manufacturing. The results, shown in table 3, generally support the previous findings. The drop in long-run output elasticity after 1961, though not quite so sharp, is still pronounced, and still statistically significant. ${ }^{17}$ Since monthly data are available they are used, although quarterly versions of the equations looked very much the same. ${ }^{18}$ Collinearity among the thirteen output variables produced a scattering of negative signs in the coefficients and these make a mean-lag calculation dubious. Instead, the percent of the long-run output effect occurring in the current month is shown and a sharp shift in timing is evident. ${ }^{19}$

Although hypotheses other than those invoking expectational effects

17. The null hypothesis that the parameters remained the same from 1949 to 1975 was rejected at the 1 percent level.

18. The long-run elasticities were very close. The quarterly estimates masked the shift in timing away from the current month revealed in table 3.

19. It was suggested to me that the rapid Korean War buildup might be responsible for the 1948-61 findings and that a dummy variable for 1950:3 to 1951:2 might alter the results. It did not do so, however, and the dummy entered with opposite signs in the regressions of tables 2 and 3. 


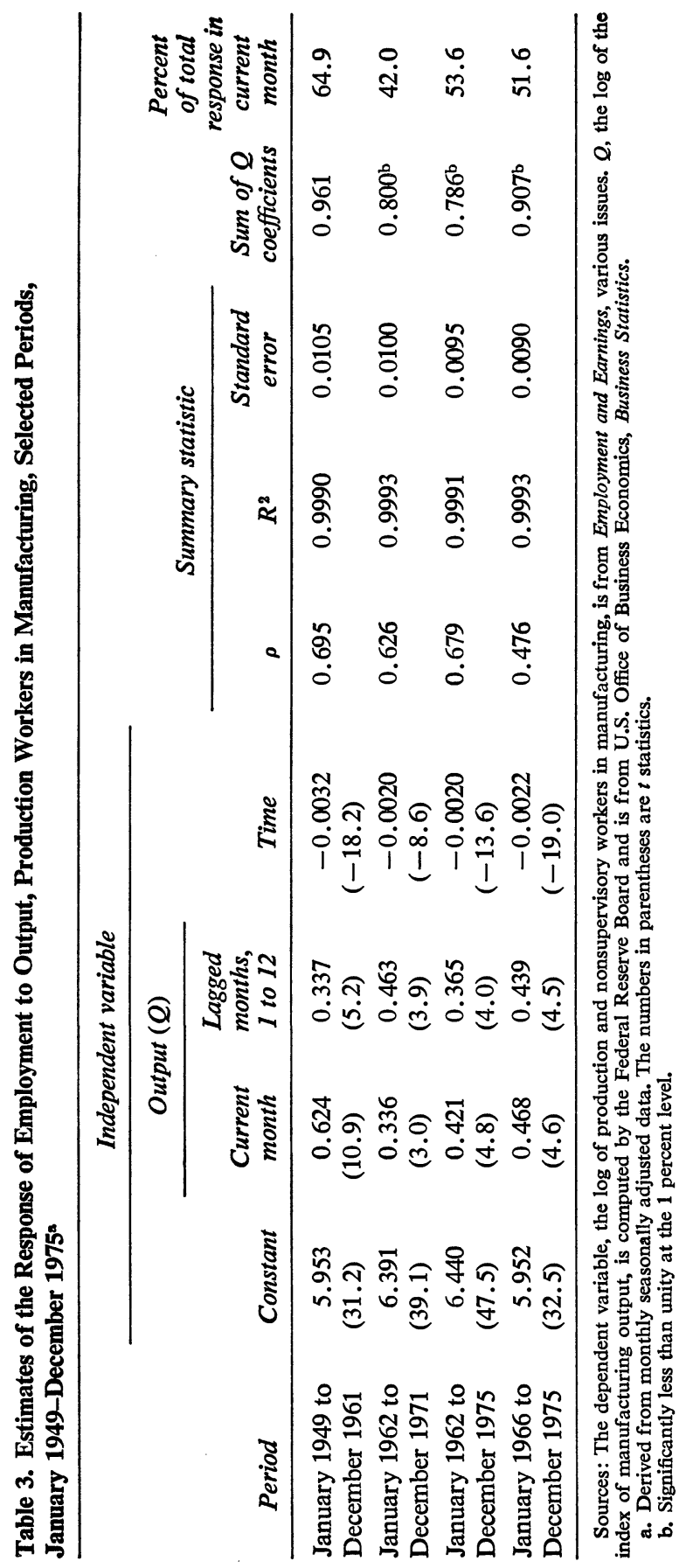


could explain these results, certain structural changes might have been expected to work in the opposite direction. First, self-employed workers will reduce their hours of work when business is slack rather than lay themselves off, and self-employment has declined. Second, both my own models and those developed by Martin Feldstein suggest that the increased coverage and generosity of unemployment insurance over the period probably encouraged layoffs. ${ }^{20}$

It was noted earlier that the seventies marked a shift in policy toward fighting inflation. In 1975 people expected an extended recession. Tables 2 and 3, particularly the latter, reveal a more complete response of employment to output in the regressions for the most recent period. Of course, the 1973-75 period was a very unusual one, and it would be dangerous to infer too much from the regression that includes it.

\section{THE RESPONSE OF INVENTORIES}

An efficient firm compares the costs of varying employment with the cost of using inventories to adjust the gap between sales and production in the short run. If firms in recent periods are varying employment less in response to a given output variation compared with earlier years, as the preceding section suggested, then they are changing behavior at the employment-output margin, and consistent change at the inventory-sales margin can be expected.

Furthermore, any change since 1948 in the relation between a distributed lag of past sales and firms' expectations of future sales also should show up. Specifically, a short-run increase in sales will raise expected sales by a smaller amount after 1961 . Similarly, a fall in sales will lower expected sales by less.

To examine these hypotheses an equation relating business inventories to final sales was run over the same subperiods. ${ }^{21}$ Table 4, which reports

20. Martin Neil Baily, "On the Theory of Layoffs and Unemployment," Econometrica, vol. 45 (July 1977), pp. 1043-63; Martin Feldstein, "Temporary Layoffs in the Theory of Unemployment," Journal of Political Economy, vol. 84 (October 1976), pp. 937-57. Some empirical evidence on this question is given in Martin Feldstein, "The Effect of Unemployment Insurance on Temporary Layoff Unemployment," discussion paper 520 (Harvard University, Harvard Institute of Economic Research, November 1976; processed).

21. A log-linear form was used because it seemed to be a natural extension of the demand for labor and for fixed capital. Besides, it fit much better. A linear specification showed similar changes in coefficients, however. The main difference is that the linear specification has a much lower long-run elasticity. 


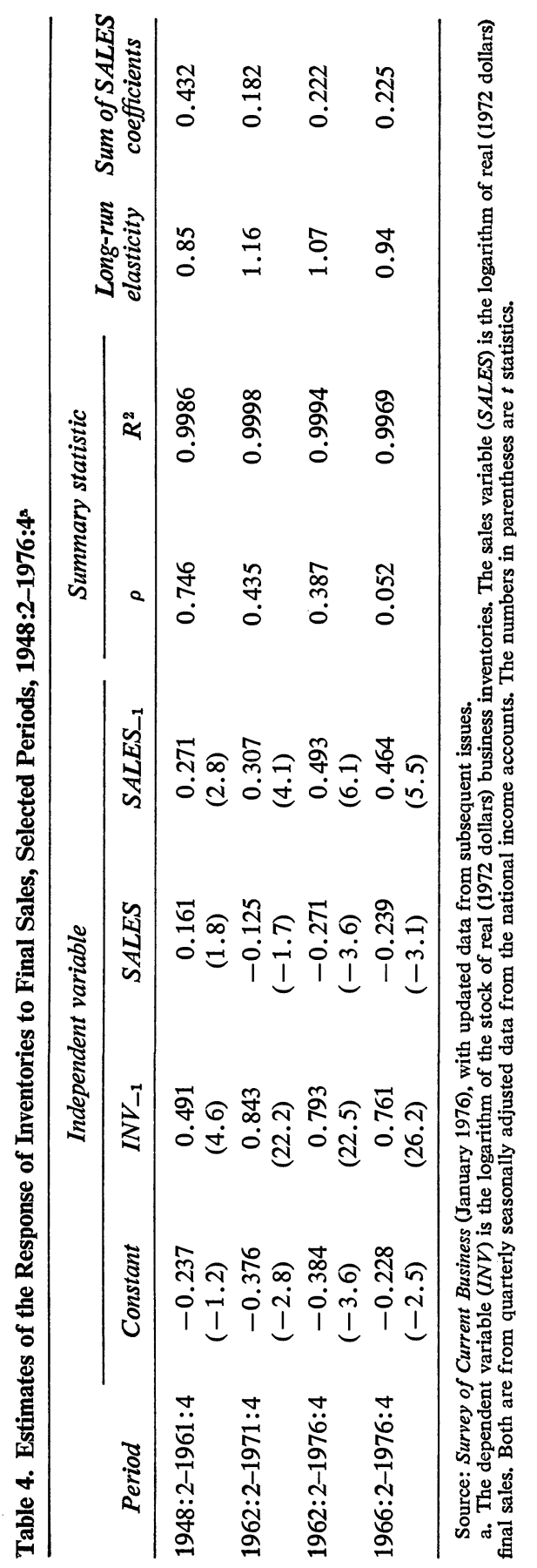


the results, shows substantial differences between the 1948-61 period and the later periods. The differences are highly significant statistically. ${ }^{22}$ The most important changes are that the lagged dependent variable has a much larger coefficient and the sum of the coefficients on sales is much smaller in the later periods. In addition, the current-sales variable changes sign.

Table 4 is intended to provide only a descriptive statement about the changing dynamics of inventories of final goods. It does not use data on sales forecasts because, as noted earlier, this would eliminate part or all that is of interest here. It does not compare models based on salesforecasting errors with models based on target adjustment. ${ }^{23}$

The descriptive picture does look consistent with the changes described above. The increase in the ratio of the coefficient of the lagged dependent variable to the sum of the coefficients of the sales variables is consistent with firms' taking a longer view when incorporating information about current and past sales into an expected sales estimate. The change of sign of the coefficient of current sales is consistent both with this notion that current sales get a smaller weight in the estimate of future sales and with the notion that a high (low) level of sales, whether or not it was predicted, is met to a greater extent by selling out of inventories (allowing inventories to build up) in the later periods.

\section{THE RESPONSE OF ORDERS FOR PRODUCERS' DURABLES}

The accelerated response of investment to changes in output has been seen as a major determinant of the business cycle and as a potentially important source of dynamic instability in the economy. The specification of the accelerator in econometric work usually assumes that firms try to gear their investment demand to changes in a desired capital stock, which depends, in turn, on the paths of output and capital costs. If firms adjust less rapidly or completely to short-run changes in output and capital cost, the accelerator parameters will change.

A difficulty with simply testing directly for changes in the accelerator

22. Null hypotheses that the parameters have remained constant from 1948 to 1971 or from 1948 to 1976 were both rejected at the 1 percent level.

23. Michael C. Lovell, "Sales Anticipations, Planned Inventory Investment, and Realizations," in Robert Ferber, ed., Determinants of Investment Behavior (Columbia University Press for the National Bureau of Economic Research, 1967), pp. 53780; Martin Feldstein and Alan Auerbach, "Inventory Behavior in Durable-Goods Manufacturing: The Target-Adjustment Model,” BPEA, 2:1976, pp. 351-96. 
is that expectational lags and delivery lags are hopelessly intertwined in the specification of investment-expenditure equations. ${ }^{24}$ Using orders rather than expenditures helps to solve the problem, but only partially because changes in delivery lags will in general imply changes in the expectation structure. Still, the response of orders to changes in output (and cost) is certainly closer to what is wanted. The MPS model contains an orders equation and this was estimated over various subperiods, with the results shown in table $5 .{ }^{25}$ Data limitations prevented the estimation of the equation prior to $1953: 2$, thereby missing several of the early and more volatile years. Further, the service-price variable does incorporate expectational information from the stock market. Both of these factors bias the findings against structural change. Nevertheless, the smoothing or dampening of the accelerator response over time is quite marked, and the timing of the response is also different. It is noticeably slower in the later periods. Very little acceleration occurred in the period 1962-71, which was dominated by the steady growth from 1962 to 1966 . With the 1972-76 period included, the accelerator makes a comeback, but only a modest one.

Despite the marked differences in the point estimates of the parameters, statistical tests do not uncover significant shifts in the function. ${ }^{26}$ Beyond the two factors given earlier, the main reason is that the likelihood function is rather flat with respect to the parameters even over the whole period, as the write-up of the MPS model notes. ${ }^{27}$

\section{The Stock Market, Interest Rates, and Inflation}

An additional piece of econometric evidence, of a different type, is also consistent with the hypothesis of changing expectations.

24. See Robert E. Hall, "Investment, Interest Rates, and the Effects of Stabilization Policies," BPEA, 1:1977, pp. 61-103. Evidence from the backlog of past orders suggests that delivery lags have probably changed over time.

25. The data were supplied by the staff at the Federal Reserve Board. There is one difference between the equation as run here and the MPS version: first-order serial correlation is allowed for because the equation seems to require it; the estimated $\rho$ is large and significant. The changes across periods become much more pronounced if serial correlation is ignored.

26. If the MPS procedure is followed and serial correlation is ignored, then the shifts are significant.

27. "Quarterly Econometric Model" (MIT-Penn-SSRC, May 1977, preliminary; processed). 
Table 5. Estimates of the Effects of a Sustained Change in Output or Service Price on Orders for Producers' Durable Equipment over the Subsequent Eight Quarters, Selected Periods, 1953:2-1976:4a

\begin{tabular}{|c|c|c|c|c|c|c|c|}
\hline \multicolumn{2}{|c|}{ Tvpe of $\frac{1953: 2-1961: 4}{2}$} & \multicolumn{2}{|c|}{ 1962:1-1971:4 } & \multicolumn{2}{|c|}{$1962: 1-1976: 4$} & \multicolumn{2}{|c|}{$1966: 1-1976: 4$} \\
\hline $\begin{array}{l}\text { effect and } \\
\text { quarter }\end{array}$ & $\begin{array}{c}\text { Service } \\
\text { Output price }\end{array}$ & Output & $\begin{array}{l}\text { Service } \\
\text { price }\end{array}$ & Output & $\begin{array}{l}\text { Service } \\
\text { price }\end{array}$ & Output & $\begin{array}{l}\text { Service } \\
\text { price }\end{array}$ \\
\hline
\end{tabular}

Effect in each quarter as percent of long-run or steady-state effect ${ }^{\mathrm{b}}$

$\begin{array}{rrrrrrrrr}0 & 288 & 0 & 58 & 0 & 141 & 0 & 133 & 0 \\ 1 & 340 & 122 & 108 & 60 & 198 & 42 & 193 & 48 \\ 2 & 350 & 191 & 138 & 98 & 234 & 72 & 230 & 80 \\ 3 & 327 & 219 & 150 & 119 & 249 & 91 & 246 & 99 \\ 4 & 282 & 215 & 150 & 126 & 246 & 101 & 243 & 109 \\ 5 & 226 & 190 & 140 & 124 & 228 & 105 & 224 & 111 \\ 6 & 170 & 156 & 126 & 116 & 196 & 105 & 192 & 108 \\ 7 & 125 & 122 & 112 & 107 & 153 & 102 & 150 & 104 \\ 8 & 100 & 100 & 100 & 100 & 100 & 100 & 100 & 100\end{array}$

Total longrun effect, $\sum\left(b_{i}+c_{i}\right)$ 0.0170

0.0188

0.0192

Autocorrelation coefficient, $\rho$

$$
0.701
$$

0.718

0.653

0.616

Source: MPS data bank.

a. Derived from the equation

$$
O P D=0.01\left[\sum_{i=0}^{7} b_{i} V P D_{-1-i} X B_{-i}+\sum_{i=1}^{7} c_{i} V P D_{-i} X B_{-i}\right],
$$

where $O P D$ is new orders for producers' durable equipment, $V P D$ is the equilibrium ratio of producers' durables to output multiplied by a constant, and $X B$ is gross private domestic business product. $O P D$ and $X B$ are measured in 1972 dollars.

b. The long-run effect of a step change in the product $(X B)(V P D)$ is given by $\sum\left(b_{i}+c_{i}\right)$. The percent of this long-run effect in each quarter is given in the table. For further discussion see Charles W. Bischoff, "The Effect of Alternative Lag Distributions," in Gary Fromm, ed., Tax Incentives and Capital Spending (Brookings Institution, 1971), pp. 61-125, especially table 3-11 and the accompanying discussion.

Investors in the stock market seem to be very concerned with anticipating policy. The market appears to fluctuate quite sharply upon rumors of changes in policy or even changes in personnel. In order to pick up signs of the changing awareness of policy and the changing emphasis of policy itself, the pattern of correlation among four variables is considered. These are (1) Standard and Poor's index of 500 stocks; (2) the interest rate on new issues of high-grade corporate bonds (this variable also is a proxy for bond prices); (3) the consumer price index; and (4) corporate profits. All four variables were expressed as quarter-to-quarter proportional rates of change. The rate of change of the stock index was 
Table 6. Correlations among the Stock Index, Interest Rates, Prices, and Corporate Profits, Selected Periods, 1948:1-1976:4 ${ }^{\mathrm{a}}$

\begin{tabular}{|c|c|c|c|c|c|}
\hline \multirow[b]{2}{*}{ Equation and period } & \multicolumn{4}{|c|}{ Independent variable } & \multirow[b]{2}{*}{$R^{2}$} \\
\hline & Constant & $\begin{array}{l}\text { Interest } \\
\text { rate }\end{array}$ & $\begin{array}{l}\text { Consumer } \\
\text { price index }\end{array}$ & $\begin{array}{c}\text { Corporate } \\
\text { profits }\end{array}$ & \\
\hline 6-1 1948:1-1961:4 & $\begin{array}{l}0.0288 \\
(3.7)\end{array}$ & $\begin{array}{l}0.0182 \\
(0.2)\end{array}$ & $\begin{array}{l}-0.0224 \\
(-0.0)\end{array}$ & $\ldots$ & 0.0005 \\
\hline 6-2 1948:1-1961:4 & $\begin{array}{l}0.0267 \\
(3.6)\end{array}$ & $\begin{array}{l}-0.0526 \\
(-0.5)\end{array}$ & $\begin{array}{l}0.212 \\
(0.3)\end{array}$ & $\begin{array}{l}0.181 \\
(2.4)\end{array}$ & 0.0995 \\
\hline 6-3 1962:1-1976:4 & $\begin{array}{l}0.0446 \\
(3.4)\end{array}$ & $\begin{array}{l}-0.342 \\
(-2.3)\end{array}$ & $\begin{array}{l}-2.95 \\
(-3.0)\end{array}$ & $\ldots$ & 0.2446 \\
\hline $6-4 \quad 1962: 1-1976: 4$ & $\begin{array}{l}0.0432 \\
(3.3)\end{array}$ & $\begin{array}{l}-0.347 \\
(-2.3)\end{array}$ & $\begin{array}{l}-2.90 \\
(-2.9)\end{array}$ & $\begin{array}{l}0.0406 \\
(0.4)\end{array}$ & 0.2465 \\
\hline 6-5 1966:1-1976:4 & $\begin{array}{l}0.0648 \\
(3.4)\end{array}$ & $\begin{array}{l}-0.390 \\
(-2.6)\end{array}$ & $\begin{array}{c}-3.97 \\
(-3.1)\end{array}$ & $\ldots$ & 0.3390 \\
\hline 6-6 1966:1-1976:4 & $\begin{array}{l}0.0637 \\
(3.2)\end{array}$ & $\begin{array}{l}-0.394 \\
(-2.5)\end{array}$ & $\begin{array}{l}-3.93 \\
(-3.0)\end{array}$ & $\begin{array}{l}0.0394 \\
(0.3)\end{array}$ & 0.3409 \\
\hline
\end{tabular}

Source: Business Conditions Digest, various issues.

a. All variables are expressed as quarter-to-quarter proportional changes. The dependent variable is Standard and Poor's 500-stock index. The interest-rate variable is the rate on new issues of high-grade corporate bonds. The numbers in parentheses are $t$ statistics. The consumer price index and corporate profits are seasonally adjusted.

used as the dependent variable and the other rates of change are independent variables, although no assertion about causality is made. The results, given in table 6 , trace a fairly clear pattern. Neither the interest rate nor the CPI is correlated with the stock market in 1948-61. Corporate profits is the only statistically significant variable, showing a positive correlation. The periods $1962-76$ and $1966-76$ show very different results. The shift in the parameters between these periods and 1948-61 is statistically significant. The corporate-profits variable totally loses significance while the interest-rate and CPI variables acquire large significant coefficients.

These findings are consistent with the following analysis. Substitution between bonds and stocks in portfolios always suggests that a rise in the interest rate will depress stock prices ceteris paribus. In the period 194861 a business expansion simultaneously (1) raised interest rates, (2) raised corporate profits, and (3) raised profits expectations. The combination of the second and third factors explains the significant coefficient on profits. The interest-rate coefficient remained negative but small as the positive correlation between stock prices and the interest rate implied by 
equation 6-1 almost offsets the portfolio-substitution effect. After 1962, and especially after 1966 when the fight against inflation was so important, a general business expansion and rise in profits no longer generated the expectation of more of the same. The decline of the profits coefficient reflects this development. The interest-rate coefficient becomes large and significant, reflecting both the predominance of the portfolio-substitution effect and the fact that rising interest rates signal contractionary policy. Similarly, in the later periods, again especially in 1966-76, the strong negative coefficient on the inflation variable is consistent with stockmarket fears that inflation will lead to future contractionary policies. ${ }^{28}$

I tried a couple of variations on table 6 . The interest rate on Treasury bills performed in much the same way as the rate on new corporate issues. The lagged value of the inflation variable entered with the opposite sign to the current inflation rate, indicating that any acceleration of inflation as well as the level might be important. But the coefficients were insignificant.

\section{Anticipated and Unanticipated Policy: Some Analytical Issues}

In this section a simple illustrative model is developed in which fiscal policy is used to offset fluctuations in the level of real aggregate demand. For the present it is assumed that fluctuations in aggregate demand are simply met by corresponding variations in the level of output supplied. I assume that firms have rational expectations about the behavior of the economy when they make investment decisions; they may or may not anticipate the offsetting policy actions, and I contrast the two cases. The approach used considers the consequences of anticipating policy, while rejecting the assumption of complete price flexibility. I begin in this section with the extremely simplified assumptions of no price flexibility and no interest-rate responsiveness; the next section suggests how the results obtained here must be modified when prices and interest rates also respond. A discrete-time framework is used with unsubscripted variables referring to time $t$ and pluses and minuses referring to periods earlier or later than $t\left(x_{+1}\right.$ is the value of $x$ in period $t+1$, for example). Aggre-

28. The generally weak performance of the stock market in the last ten years has coincided with higher average rates of inflation. One might link both events to other causes. But the regression is on quarter-to-quarter changes, not on levels. 
gate demand has its usual components: investment, consumption, and government demand.

Investment demand in period $t$ depends upon adjustment to a desired capital stock, $k^{d e s}$. With $x_{+1}^{e}$ the expected level of real output in $t+1$ and $v$ the desired capital-output ratio,

$$
k_{+1}^{d e s}=v x_{+1}^{e} .
$$

A one-period delivery-installation lag for investment goods is assumed, and investment demand $(i)$ is then specified by

$$
i=v x_{+1}^{e}-(1-\delta) k
$$

where $\delta$ is the depreciation rate and $k$ is the actual stock of capital in period $t$. More realistically, one could assume that delivery might be spread over more than one period and that firms would worry about being stuck with excess capital. Such considerations would modify the results derived here, but would not change their basic character.

Government demand is set by policy and is denoted by $g$. Poll taxes are raised to finance this expenditure in an amount $\phi$, and the budget is assumed always to be balanced:

$$
g=\phi
$$

Gross output $(x)$ less taxes paid $(\phi)$ constitutes income available to the household sector $(y)$ :

$$
y=x-\phi=x-g .
$$

Consumption demand is based upon $y^{*}$, the long-run equilibrium value of income (discussed further below) and $y$, current income: ${ }^{29}$

$$
c=\beta\left[\lambda y^{*}+(1-\lambda) y\right]+\epsilon, \quad 0 \leq \lambda \leq 1 .
$$

If $\lambda=1$, the specification says that consumers save a constant fraction of their permanent income; if $\lambda<1$, consumption is influenced by transitory income. The term $\epsilon$ is transitory consumption, the source of random

29. The specification of 5 involves a minor simplification because it does not start with permanent income defined as the present discounted value of expected future income. If instead of 5 , consumption were made proportional to $y^{e}$, defined by $(1-\lambda) \sum_{0}^{\infty} \lambda^{\tau} y_{+\tau}^{e}$, the model's main conclusion would carry through. The algebra involved in the backward recursion to be used below becomes much more burdensome, however. 
shocks in the system from, for example, distributional effects or variations in consumer sentiment. It will be assumed further that $\epsilon$ is positively serially correlated - that is, that a positive or negative disturbance may persist over time.

$$
\epsilon=\rho \epsilon_{-1}+\eta, \quad 0<\rho<1,
$$

where $\eta$ is serially uncorrelated with mean zero.

Let $x^{*}$ be the target or desired level of output and assume this target level is stationary over time. In the absence of any random shock $(\epsilon=0)$ this target level of output can be achieved by a level of government expenditure $\left(g^{*}\right)$ given by

$$
g^{*}=x^{*} \frac{1-\beta-\delta v}{1-\beta},
$$

where $0<g^{*}<x^{*}$ provided $\beta+\delta v<1$. Such an equilibrium solution is characterized by (1) a stationary capital stock, $k^{*}=v x^{*} ;(2)$ gross investment equal to $\delta k^{*}$ (net investment zero); and (3) gross saving $(1-\beta) y^{*}=(1-\beta)\left(x^{*}-g^{*}\right)$ also equal to $\delta k^{*}$ (net saving zero). The condition $\beta+\delta v<1$ is the condition that the marginal propensity to consume (MPC) out of long-run gross income (output less taxes) and the marginal propensity to invest out of GNP sum to less than unity. Without this there is no "room" for government expenditure. ${ }^{30}$

THE RESPONSE OF THE ECONOMY TO RANDOM SHOCKS: NO POLICY

Consider a situation in which the economy has been in equilibrium at $x=x^{*}$ with no shocks impinging on the system. What is the response of the economy to a shock in period $t, \epsilon \neq 0$, in the absence of any policy action-that is, when $g^{*}$ prevails in all periods? The absence of any policy action is a fact known to all persons in the economy so that

$$
g_{+s}=g_{+s}^{e}=g^{*}, \quad s \geq 0 .
$$

The shock $\epsilon$ has a direct impact on aggregate demand in period $t$ and,

30. In a more complete model, either a change in the interest rate that altered $v$ (and perhaps $\beta$ ) or an unbalanced government budget would provide more flexibility in setting $g$. 
therefore, on output in $t$. But it also has two indirect impacts. The first is the usual consumption response occurring through $\beta(1-\lambda)$, the MPC out of current income. The second is through investment. Investment demand in $t$ depends upon the expected level of output in period $t+1$, which in turn depends upon the level of investment in period $t+1$. Investment in $t+1$ depends upon expected output in $t+2$, and so on. Thus, without some way of tying the process down, one can chase a rainbow indefinitely in an attempt to evaluate the rational expected path of output and investment.

Even with rational expectations an unstable response is not impossible. The usual rationale for ruling out unstable trajectories is that they must hit either a floor or a ceiling in finite time. Then if people anticipate the floor or ceiling, the unstable trajectory was not rational. I will invoke this argument here and assume that there are stable expectations in the sense that $x_{T}^{e} \rightarrow x^{*}$ as $T \rightarrow \infty$. This is a strong assumption to make; it requires not just short-run rationality but long-run foresight.

The method of using stability to solve out for the expected path of output is as follows. Assume that for some large $T, x_{T+1}^{e}=x^{*}$ and $\epsilon_{T+1}^{e}=0$. This permits writing down expected output in period $T$, given by

(9) $x_{T}^{e}=\beta\left[\lambda x^{*}+(1-\lambda) x_{T}^{e}\right]+(1-\beta) g^{*}+\epsilon_{T}^{e}+v x^{*}-v(1-\delta) x_{T}^{e}$.

This can be simplified to

$$
x_{T}^{e}=\frac{b}{a}+\frac{1}{a} \epsilon_{T}^{e}+\frac{v}{a} x^{*},
$$

where $a \equiv 1+v(1-\delta)-\beta(1-\lambda)$ and $b \equiv(1-\beta) g^{*}+\beta \lambda x^{*}$. With this endpoint determined it is possible to solve backward for $x_{T-1}^{e}, x_{T-2}^{e}$, and so on, and then use a limit process to let $T \rightarrow \infty$. This is easy enough to do, and the details are given in the appendix. It yields the result

$$
x_{+s}^{e}=\frac{b}{a-v}+\frac{\rho^{s} \epsilon}{a-\rho v}=x^{*}+\frac{\rho^{s} \epsilon}{a-\rho v}
$$

for the expected level of output for period $t+s$, $s$ periods into the future. In particular, $x_{+1}^{e}$ is given by

$$
x_{+1}^{e}=x^{*}+\frac{\rho \epsilon}{a-\rho v} .
$$

Now that a value of expected output for period $t+1$ has been found, the 
backward recursion can be completed and the value of current output found. The variable $x$ is given by

$$
\begin{aligned}
x & =\beta\left[\lambda y^{*}+(1-\lambda) y\right]+\epsilon+v x_{+1}^{e}-(1-\delta) v x^{*}+g^{*} \\
& =x^{*}+\frac{a \epsilon}{[1-\beta(1-\lambda)](a-\rho v)},
\end{aligned}
$$

where equation 12 has been substituted into 13 .

Equations 11, 12, and 13 give the initial response and expected output path of this simple economy following the aggregate-demand shock. The interpretation of 13 is that the demand shock $\epsilon$ is modified by an expression that is the product of two terms. The first term is $1 /[1-\beta(1-\lambda)]$, where $\beta(1-\lambda)$ is the MPC out of current income. Thus the first term is the familiar multiplier expression. The second term is $a /(a-\rho v)$. If $\rho=0$, this term is unity. If the random shock $\epsilon$ is serially uncorrelated, it causes no change in investment demand. The size of the capital stock in period $t$ is not what would have been chosen had the shock $\epsilon$ been anticipated, but the desired capital stock for $t+1$ is unaltered-given $\rho=0$.

The interesting case for the model is one in which $0<\rho<1$. The second term is then strictly greater than unity and the investment response amplifies the impact of the demand shock in combination with the simple multiplier.

The result just stated turns out to be the most important to the comparison of anticipated and unanticipated policy. But a complete comparison of the two cases also depends upon whether or not the investment response amplified the lingering effects of the initial shock; these lingering effects are expected to be $\rho \epsilon, \rho^{2} \epsilon$, and so on in successive periods.

The deviation of $x_{+s}^{e}$ from $x^{*}$ is just $\rho^{s} \epsilon$ multiplied by the expression

$$
(a-\rho v)^{-1}=[1+v(1-\delta-\rho)-\beta(1-\lambda)]^{-1} .
$$

If investment were fixed in this model, this expression would reduce to the multiplier-only case $[1-\beta(1-\lambda)]^{-1}$. Thus whether the investment response amplifies or diminishes the deviation of $x_{+s}^{e}$ from $x^{*}$ depends on whether $\rho$ is greater or less than $(1-\delta)$. Formally,

$$
\frac{1}{a-\rho v} \lesseqgtr \frac{1}{1-\beta(1-\lambda)} \text { as } \rho \leqq(1-\delta) \text {. }
$$

The case $\rho<(1-\delta)$ seems much the most likely one so I will call it the normal case. In analyzing the response of the economy to the initial shock, 
a positive shock $(\epsilon>0)$ unequivocally raises investment $\left(i>i^{*}\right)$. However, in the normal case, the opposite is true for expected investment in future periods. A positive shock $\epsilon>0$ leads to $i_{+s}^{e}\left\langle i^{*}\right.$ for $s>0$. Thus making investment endogenous implies that expected output is a little closer to its long-run equilibrium value than would be true in a multiplieronly model. Deviations of $i_{+s}^{e}$ from $i^{*}$ somewhat offset the deviations of consumption from its long-run value. ${ }^{31}$

What explains the fact that a positive (negative) shock in period $t$ results in lower (higher) future investment? The reason is simply that although expected output is always greater than $x^{*}$ following a positive demand shock, it is nevertheless falling over time. If $x_{+s}^{e}<x_{+s-1}^{e}$, then $i_{+s}^{e}<i^{*}$ even though $x_{+s}^{e}>x^{*}$. This is just a usual accelerator response. Finally, why is the condition $\rho<(1-\delta)$ necessary to all this? The preceding story is always true for net investment. Net investment is zero in equilibrium. A positive demand shock induces positive net investment in the same period; the capital stock is increased to match the higher expected level of output in future periods. Net investment is then negative in future periods; the capital stock is adjusted back to its equilibrium level as output converges to $x^{*}$. If the rate of depreciation were very rapid and the demand shock were expected to persist-that is, if $\rho>(1-\delta)$-then gross investment would be increased in all periods by a positive demand shock. The negative net investment would be offset by the larger replacement investment required by the larger capital stock.

\section{UNANTICIPATED FISCAL POLICY}

It will now be assumed that government expenditure is varied in response to the demand shock in an attempt to restore the target level of output $x^{*} .^{32}$ Policy actions are not anticipated, however, so that it remains true that

$$
g_{+s}^{e}=g^{*}, \quad s>0 .
$$

Consider, as before, a situation in which the economy has been operating in equilibrium and is then hit by an unanticipated shock $\epsilon$. This shock is a surprise to the policymakers, so that government expenditure in

31. In fact $1 /(a-\rho v)$ could be less than unity. This would require $\beta(1-\lambda)$ $<v(1-\rho-\delta)$. The term $(a-\rho v)$ is always positive, so that there is no question of a positive shock now causing expectations of a recession.

32. The budget remains balanced, however; $g=\phi$ in all periods. 
period $t$ has already been set at $g^{*}$. Because of 15 it follows that the private sector's expectations of output, $x_{+1}^{e}, x_{+2}^{e}$, and so on, are given, just as before, by equation 11 . The response of investment, therefore, is already worked out for the unanticipated policy case. The response of the economy in period $t$ to the initial shock is again given by equation 13 .

Although the policymakers do not know the actual value of the disturbance $\epsilon_{+1}$, they do know its expected value $\rho \epsilon$. They can, therefore, estimate the fiscal policy necessary in period $t+1$ to restore expected equilibrium. If $g_{+1}^{u n}$ is the level of government expenditure required to restore equilibrium (to make the true expectation of $x_{+1}$ equal $x^{*}$ ) when the policy is unanticipated, then

$$
g_{+1}^{u n}=g^{*}-\frac{\rho \epsilon}{a-\rho v} .
$$

The deviation of $g_{+1}^{u n}$ from $g^{*}$ is just equal (and opposite) to the deviation of $x_{+1}^{e}$ from $x^{*}$ from equation 12 , because the balanced-budget multiplier relevant for unanticipated policy is unity. ${ }^{33}$

\section{ANTICIPATED FISCAL POLICY}

In this case, government expenditure is set in periods $t+1, t+2$, and so on in such a way that the expected level of output in these periods is always $x^{*}$, and investment decisions are made with this knowledge. The initial shock $\epsilon$ is not offset by policy because it was a surprise, but the impact of $\epsilon$ on investment in $t$ resulted not directly from the initial shock, but indirectly because of the expected lingering impact of the shock $\left(\rho \epsilon, \rho^{2} \epsilon\right.$, and so on). If these expected effects are offset, then there is no response of investment to the demand shock $\epsilon$. Thus output $x$, in this case, is given by

$$
x=x^{*}+\frac{\epsilon}{[1-\beta(1-\lambda)]} \text {. }
$$

33. The balanced-budget multiplier is a partial concept in this context. Suppose policymakers ask themselves in some period, what would happen to output if we made an unexpected change in $g$ that was not expected to persist? They would answer this from

This gives

$$
x=\beta\left[\lambda y^{*}+(1-\lambda)(x-g)\right]+g+v \delta x^{*} .
$$

$$
d x=\beta(1-\lambda)(d x-d g)+d g, \text { or } d x / d g=1 .
$$

Equation 7 gives the long-run sustainable relation between $x^{*}$ and $g *$ with the impact on the long-run capital stock included. 
The magnitude of the change in fiscal policy needed for expected equilibrium in period $t+1$ also reflects the fact that investors now anticipate policy:

$$
g_{+1}^{a n t}=g^{*}-\frac{\rho \epsilon}{1-\beta(1-\lambda)},
$$

where $g_{+1}^{a n t}$ is the level of government expenditure required when policy is anticipated.

The anticipated-policy case is very much like a multiplier-only model with constant investment. Investment remains constant at $i^{*}$, not because it is arbitrarily fixed, but because expected output is always equal to $x^{*}$.

\section{COMPARISON OF ANTICIPATED AND UNANTICIPATED CASES}

The first and most important difference between the cases of anticipated and unanticipated policy is that the initial response of the economy to an unexpected demand shock is unequivocally smaller when policy is anticipated. Just thinking about stabilization policy can make people feel better about the economy. The model, therefore, provides illustrative support for the confidence effect, or "FDIC effect," noted earlier.

It is often argued that lags impede the efforts of fiscal policy to stabilize the economy. It takes time to make even incremental changes in taxes and expenditures. ${ }^{34}$ This analysis has shown that anticipated fiscal policy can have a desirable impact even before it has been enacted. This is not to say that the lag is a good thing; it is not. But it may not be quite such a problem as has been suggested.

When the policy is enacted in period $t+1$, is more or less of it required as a result of its being anticipated? Most of the work to answer this question has been done already. Comparing equations 16 and 18, and using 14 , gives

$$
\left|g_{+1}^{a n t}-g^{*}\right| \gtreqless\left|g_{+1}^{u n}-g^{*}\right| \text { as } \rho \lesseqgtr(1-\delta) \text {. }
$$

The normal case described earlier, where $\rho<(1-\delta)$, requires that the change in policy be larger when that policy is anticipated. The reason goes back to the earlier discussion of the response of investment. When policy

34. This was incorporated in the analysis because when the disturbance $\epsilon$ strikes, investors are able to respond in the same period by altering investment demand (if they wish). By assumption, however, $g$ remains fixed until the subsequent period. 
is anticipated, investment demand is unaffected by the disturbance $\epsilon$. The model behaves like a multiplier-only model. The main consequence is that stability is improved in the period when $\epsilon$ strikes-as noted abovebut another is that the offsetting effect from the adjustment of the capital stock back to its long-run equilibrium level is lost. Any smoothing of the accelerator makes investment fall less sharply in a recession, but also pick up less in the recovery.

\section{REDUCED-FORM OR STRUCTURAL INFORMATION}

In the analysis of anticipated policy, firms formed rational expectations of the policy change; in fact, they knew what level of government expenditure would be set. The conclusions do not depend, however, on the assumption that firms understand the structure of the model. In the analysis of the model without policy, they could have learned the appropriate response to a shock $\epsilon$, so that the path of output given in equations 11 and 13 need not imply structural information. When policy is introduced, firms may simply learn by experience that an initial disturbance of a given magnitude no longer induces the same path of output. They may attribute this to a change in the pattern of serial correlation of the disturbance, or they may not even be concerned about the underlying structure. ${ }^{35}$

In order to set policy correctly, an understanding of the structure is almost essential. Reduced forms of past behavior can give a misleading guide to policy, as Robert Lucas has pointed out. ${ }^{36}$ First, the required fiscal policy to restore expected equilibrium is different in the anticipated and unanticipated cases. Second, and perhaps the greater danger, policymakers may not perceive correctly the magnitude of the initial disturbance $\epsilon$ when the response of the private economy has been altered. Any rule of thumb that requires that a recession of a certain size should be countered by a stimulus of a certain size will start to go wrong.

It is not absolutely essential that either side fully understand the structure, however. One could construct a model of adaptive behavior in which firms gradually learn that cycles are changing, while policymakers grad-

35. If policy were literally as effective as is stated in this model-that is, if it were always set to restore expected equilibrium-firms would seem to discover that disturbances are no longer serially correlated. In practice, of course, policy never has gone this far. The conflicting goals of controlling inflation and maintaining full employment have made actual policy more complex.

36. Lucas, "Econometric Policy Evaluation." 
ually learn that the response of the private sector is changing. Eventually, there could be a convergence to behavioral and policy rules that look rational, in that neither firms nor policymakers are consistently surprised by the reactions of the others.

\section{PRICES, MONEY, AND MONETARY POLICY}

The conclusions concerning anticipated and unanticipated fiscal policy carry over qualitatively to an economy with money and with some price flexibility. Also, the same framework can be applied to analyzing monetary policy, although the difficulty of finding an explicit solution for the path of the monetary economy limits the analysis to a general discussion of some of the main issues.

The model starts with an adjustment equation for the price level, $P$ :

$$
\frac{\Delta P}{P}-\frac{\Delta P_{-1}}{P_{-1}}=\gamma\left(\frac{x-x^{*}}{x^{*}}\right),
$$

where $\Delta P$ equals $\left(P-P_{-1}\right)$. This expression says that inflation accelerates or decelerates depending upon the GNP gap. Hence a disturbance to aggregate demand now causes a price as well as a supply (output) response. Almost any reasonable partial-adjustment specification would do as well as equation 20 . The main specification that is ruled out is one with $\Delta P / P-(\Delta P / P)^{e}$ on the left-hand side, which would give, effectively, complete price flexibility.

To the price equation add a simple equation relating the LM curve and money demand:

$$
\frac{M}{P}=b x^{\mu} R^{-\theta},
$$

where $M$ is the nominal money supply, $b$ is a coefficient, $R$ the nominal interest rate on one-period bonds, $\mu$ the income elasticity of money demand, and $\theta$ the interest elasticity. Let $r^{e}$ be the expected real rate of interest in period $t$, defined approximately by

$$
r^{e}=R-\left(\frac{\Delta P}{P}\right)^{e}
$$

Assume now that the model economy described previously, with the addition of equations 20,21 , and 22 , has a long-run equilibrium in which 
the nominal money supply grows at a constant rate $n$. The equilibrium is described by

$$
x=x^{*}, c=c^{*}, i=i^{*}, g=g^{*}
$$

and

$$
\Delta P / P=n, R=R^{*}, r^{*}=R^{*}-n .
$$

How are the real and monetary sectors linked in the context of shortrun fluctuations? Because the model has not included separate prices for capital goods and consumption goods, capital gains or losses on the physical capital stock are ruled out. ${ }^{37}$ The impact on consumption of changes in real wealth through changes in the real value of government financial liabilities is certainly small. Movements of the real interest rate might thus be the main link between the real and monetary sectors. Anything that can be said about the response of the real interest rate to the disturbance $\epsilon$ applies to the earlier findings.

\section{RESPONSE TO A DEMAND DISTURBANCE: NO OFFSETTING} POLICY

Three forces influence the real interest rate following the disturbance $\epsilon$ : (1) the change in output alters the transaction demand for money and hence the nominal interest rate; (2) the change in the price level alters real money balances, also changing the nominal interest rate; and (3) the change in the expected rate of inflation alters the real rate of interest, for any given nominal rate.

The reason the outcome is ambiguous is because of the third effect, which acquires special importance in models with rational expectations. ${ }^{38}$ This is because, in such models, even short-run fluctuations in the inflation rate will be anticipated.

37. This is not to say such changes are unimportant in practice. Excluding this effect is clearly a weakness, but adding another price also greatly complicates the specification.

38. This effect has been known for a long time. Don Patinkin devoted a good deal of space to the question in "Price Flexibility and Full Employment," American Economic Review, vol. 38 (September 1948), pp. 543-64. James Tobin has consistently emphasized the issue at least since "Money and Economic Growth," Econometrica, vol. 33 (October 1965), pp. 671-84. 
The interaction among the three effects given above can be described by the following. Equation 21 says that, as an approximation,

$$
\frac{\Delta M}{M}-\frac{\Delta P}{P}=\frac{\mu \Delta x}{x}-\theta \frac{\Delta R}{R} .
$$

By assumption $M$ grows at a rate $n$ throughout. Also by assumption the economy was in equilibrium in period $t-1$ with $\Delta P_{-1} / P_{-1}=n$ and $x=x^{*}$. Thus equation 20 gives

$$
\frac{\Delta P}{P}-n=\gamma \frac{\Delta x}{x}
$$

so that 24 and 25 give

$$
\frac{\Delta R}{R}=\frac{\Delta x}{x}\left(\frac{\mu+\gamma}{\theta}\right)
$$

The deviation of actual inflation in $t$ from its equilibrium rate $n$ (as given by 25 ) is correctly anticipated, so that equation 22 gives

$$
\Delta r^{e}=\Delta R-\gamma \frac{\Delta x}{x}
$$

which, with 26 , gives

$$
\Delta r^{e}=\frac{\Delta x}{x}\left(\frac{R \mu+R \gamma-\gamma \theta}{\theta}\right) .
$$

The three terms in the numerator of the parentheses are the three effects given above. ${ }^{39}$ Consider the following parameter estimates: (a) the interest elasticity of the demand for money equals 0.2 and the income elasticity equals 0.7 ; (b) a 5 percent decline in GNP cuts the inflation rate 1 percent $(\gamma=0.2)$; (c) the nominal interest rate is 6 percent. Then $(0.042+0.012-0.04)=0.014$ for the value of the term in parentheses in equation 27 . These parameters imply that the real interest rate is reduced by 7 basis points for each 1 percent reduction in output. ${ }^{40}$ This

39. Equation 27 depends upon the nominal interest rate and is, therefore, not invariant to the equilibrium growth rate of money, $n$. The reason for this is that equation 20, which is modeled after Phillips-curve specifications, gives the absolute change in the inflation rate, not, for example, the proportional change. If 20 is correct, then 27 should depend upon $n$.

40. The right-hand side of 27 becomes $0.07 \times \Delta x / x$. 
is not a terribly large effect, and so it suggests that equation 13 was a reasonable first approximation to the initial response of the economy, even with the money-price side of the picture included.

Trying alternative values of $\gamma$ in equation 27 illustrates that price flexibility hurts stability in the first instance. If $\gamma$ is zero (no flexibility), the real interest rate falls by 21 basis points for each 1 percent fall in output. For $\gamma>0.43$, movements in the real interest rate are destabilizing.

In the longer run, of course, price flexibility will have a cumulative effect on the price level that is certainly stabilizing. As the path of the economy develops over time, the persistent deviation of output from its equilibrium will result in a persistent deviation of the inflation rate from the growth rate of the nominal money supply. Unless the path of output starts to diverge unstably, the cumulative effect will outweigh the other forces on the real interest rate. The real interest rate will then move further, always in the same direction as the disturbance.

Finally, price effects rule out the monotonic convergence of the economy to its equilibrium that was a feature of the previous analysis. In order to return to its long-run equilibrium the economy must restore the equilibrium level of the real money supply. But since this has been disturbed by output movements on one side of $x^{*}$, it must be restored by output on the other side of $x^{*}$. At least one full cycle must follow a demand disturbance.

\section{ANTICIPATED AND UNANTICIPATED POLICY}

Suppose that monetary rather than fiscal policy is used to restore expected equilibrium in period $t+1$ and subsequent periods. If the policy is not anticipated, the initial response of the economy is the same as that in the no-policy case described above. Thus it is also true for monetary policy that, when policy is anticipated, the initial response of the economy is modified and is more stable. The reasoning is the same: investment does not respond to the disturbance.

Furthermore, like the change for anticipated fiscal policy, and for the same reason, the needed change is larger for anticipated monetary policy. This is especially true when prices adjust. Since the response of the economy in period $t$ was smaller, the deviation of the rate of inflation from its long-run value $n$ is also smaller. Thus the endogenously stabilizing adjustment of real money balances is smaller as a result of anticipated policy and so policy has more to do. 


\section{Wage and Price Setting and Anticipated Policy}

The preceding section simply assumed a price equation (equation 20) without inquiring whether this equation itself might be directly influenced by the existence of active policy.

Some observers suggest that a growing awareness of stabilization policy has caused the apparent inflationary bias that has characterized the postwar economy. ${ }^{41}$ The argument is that wages and prices are not restrained during a downturn as they once were, because downturns are seen as temporary. Firms and workers know that wage and price increases will be accommodated by expansion of the money supply or fiscal stimulus. This argument suggests that while stabilization policy may be able to influence real output, nevertheless it inherently contains the seeds of chronic inflation.

Now perhaps actual policy in the postwar period has contained an inflationary bias, but there is no inherent asymmetry of inflationary bias in stabilization policy per se. If policymakers are committed to maintaining a target level of output, either positive or negative departures from this target will be offset by policy action. Thus while recessions may become less effective in restraining inflationary wage increases, so also will booms cause less acceleration of wage inflation.

Several routes have been suggested for inflationary bias to get into policymaking. A familiar story concerns the misestimate of the long-run tradeoff through ignoring the built-in or expected rate of inflation. It is not clear that such arguments are correct. The preoccupation in the last few years with inflation at the expense of unemployment is evidence against them, while the fiscal and monetary expansion of the late 1960s (which is the source of a large part of the inflation problem) was motivated substantially by noneconomic factors. But whether correct or not, the arguments do not undermine the analytical foundations of stabilization policy.

In fact, there is an argument that stabilization policy lends a helping hand in allowing the economy to operate at a lower average rate of unemployment without accelerating inflation. The price-adjustment equation

41. For example, Fellner, Towards a Reconstruction of Macroeconomics, discusses this view, and Fellner's thinking on this point has been expressed in earlier work of his. 
used earlier, equation 20, was linear in the GNP gap. But there is a widely held view that the relation between inflation and excess demand or supply is convex from below. Conventional Phillips curves are estimated with the reciprocal of the unemployment rate $(u)$ as the cyclical variable. Take the following:

$$
\frac{\Delta P}{P}=\gamma\left(\frac{1}{u}-\frac{1}{u^{*}}\right)+\frac{\Delta P_{-1}}{P_{-1}} .
$$

To avoid accelerating inflation the following condition is required:

$$
E\left(\frac{1}{u}-\frac{1}{u^{*}}\right)=0 \text {. }
$$

With no fluctuations at all, the economy can operate at a nonaccelerating-inflation rate of unemployment (NAIRU), or natural rate, of $u^{*}$. If $u$ varies over time, the condition implies

$$
E(u)>u^{*},
$$

and

$$
\frac{E(u)-u^{*}}{u^{*}} \approx(\text { coefficient of variation of } u)^{2} .
$$

Thus the extent to which the average unemployment rate must exceed the nonstochastic NAIRU depends upon the variability of the economy-a simple consequence of the convexity of the Phillips curve. A reduction in the variance of unemployment over time is like a reduction in unemployment dispersion across labor markets at a moment in time. If the current or recent unemployment rate is no longer an adequate variable in the Phillips curve, the story will have to be changed. But the same basic idea will hold if there is a convex relation between the inflation rate and the appropriate cyclical variable.

\section{Conclusion}

Two main strands run through recent thinking concerning the interactions between stabilization policy and private economic behavior. The first is that private economic behavior will be altered by the existence of active policy. The second is that policy will become ineffective if it is an- 
ticipated. This paper has offered support for the first of these ideas and has disagreed with the second.

Any individual piece of the empirical evidence in itself would not convincingly demonstrate policy-induced changes in private economic behavior; but the cumulative effect of the equations is suggestive. Perhaps the findings for employment are the most striking. Whatever the cause of the shifting responses, the results do show that cyclical patterns have changed since World War II in ways that require some explanation.

The inferences that should be drawn from this paper are limited and should be handled with care. The results generally indicate that the shortrun response of the economy has become more stable. But only a very few sectors were considered and structural changes elsewhere may have offset any policy-induced increase in endogenous stability. For example, purchases of consumer durables are now a much larger fraction of consumer expenditure and the behavior of consumer demand for durables is quite volatile. The United States is now more influenced by the world economy and this change has affected stability.

The theoretical analysis was intended to illustrate a certain viewpoint, not provide a comprehensive model. Keynesian business-cycle models have often specified rather naive behavioral relations so that a model with foresight or rational expectations may provide a useful counterpoint.

The model may offer a new perspective in still another way. Simple models often require choosing either to focus on income and expenditure and view a recession as a deficiency of real aggregate demand, or to focus on money and the price level and view a recession as a divergence between the actual and the equilibrium price level. Obviously, a synthesis of the two is better than either one separately. But the first approach does seem to lead to a different view of anticipated policy and its effectiveness.

APPENDIX

Solving for the Effects of Random Shocks

Consumption $c$ is given by

$$
c=\beta\left[\lambda y^{*}+(1-\lambda) y\right]+\epsilon .
$$


But $y^{*}=x^{*}-g^{*}$ and $y=x-g^{*}$ when government expenditure is assumed constant. Thus $x$ is given by

(A-2) $\quad x=\beta\left[\lambda x^{*}+(1-\lambda) x\right]+(1-\beta) g^{*}+\epsilon+v x_{+1}^{e}-v(1-\delta) x^{*}$.

Solving for $x$ requires knowing the expected value of output in period $t+1$-namely $x_{+1}^{e}$. This value influences the desired capital stock and hence investment. Based on what is known in $t$,

$(\mathrm{A}-3) \quad x_{+1}^{e}=\beta\left[\lambda x^{*}+(1-\lambda) x_{+1}^{e}\right]+(1-\beta) g^{*}$

$$
+\epsilon_{+1}^{e}+v x_{+2}^{e}-v(1-\delta) x_{+1}^{e} .
$$

Thus $x_{+1}^{e}$ depends upon $x_{+2}^{e}$ and similarly $x_{+2}^{e}$ depends upon $x_{+3}^{e}$, and so on. As a first approximation, assume that for some large $T, x_{T+1}^{e}=x^{*}$ and $\epsilon_{T+1}^{e}=0$ (subsequently $T$ will go to infinity). This gives

$(\mathrm{A}-4) \quad x_{T}^{e}=\beta\left[\lambda x^{*}+(1-\lambda) x_{T}^{e}\right]+(1-\beta) g^{*}+\epsilon_{T}^{e}+v x^{*}-v(1-\delta) x_{T}^{e}$, and hence

$(\mathrm{A}-5) \quad x_{T}^{e}[1+v(1-\delta)-\beta(1-\lambda)]=(1-\beta) g^{*}+\beta \lambda x^{*}+\epsilon_{T}^{e}+v x^{*} ;$

that is,

$$
x_{T}^{e}=\frac{b}{a}+\frac{1}{a} \epsilon_{T}^{e}+\frac{v}{a} x^{*},
$$

where $b$ and $a$ are defined from equation A-5.

For the previous period

(A-6) $x_{T-1}^{e}=\beta\left[\lambda x^{*}+(1-\lambda) x_{T-1}^{e}\right]$

$$
+(1-\beta) g^{*}+\epsilon_{T-1}^{e}+v x_{T}^{e}-v(1-\delta) x_{T-1}^{e} ;
$$

that is,

$x_{T-1}^{e}=\frac{b}{a}+\frac{1}{a} \epsilon_{T-1}^{e}+\frac{v}{a} x_{T}^{e}=\frac{b}{a}\left(1+\frac{v}{a}\right)+\frac{\epsilon_{T-1}^{e}}{a}\left(1+\frac{\rho v}{a}\right)+(v / a)^{2} x^{*}$,

where equation A-5 has been substituted and the property that $\epsilon_{T}^{e}=\rho \epsilon_{T-1}^{e}$ has been used. By extension,

(A-7) $x_{T-\tau}^{e}=\frac{b}{a}\left[\frac{1-\left(\frac{v}{a}\right)^{\tau+1}}{1-\frac{v}{a}}\right]+\frac{\epsilon_{T-\tau}^{e}}{a}\left[\frac{1-\left(\frac{\rho v}{a}\right)^{\tau+1}}{1-\frac{\rho v}{a}}\right]+\left(\frac{v}{a}\right)^{\tau+1} x^{*}$. 
Then, if $v / a<1$, let $T \rightarrow \infty, \tau \rightarrow \infty$, and $T-\tau=1$ to give

$$
x_{+1}^{e}=\frac{b}{a-v}+\frac{\rho \epsilon}{a-\rho v} \text {. }
$$

Then

$$
\frac{b}{a-v}=\frac{(1-\beta) g^{*}+\beta \lambda x^{*}}{1-v \delta-\beta(1-\lambda)}=x^{*}
$$

from A-5, and $a-\rho v=1+v(1-\delta-\rho)-\beta(1-\lambda)$. These values then yield the expression given in the text. The condition $v / a<1$ implies

$$
v<1+v(1-\delta)-\beta(1-\lambda),
$$

that is, $\beta(1-\lambda)+v \delta<1$. This is weaker than the already assumed condition $\beta+v \delta<1$. 


\section{Comments and Discussion}

Edmund S. Phelps: If a student asked me for a sample of good work by the best practitioners of macroeconomics I would hand over a copy of Martin Neil Baily's paper. I should think that its knowledgeable examination of wide-ranging data and its insightful analysis of an ingenious dynamic model would make a very good impression.

The theoretical portion of the paper aims to do for balanced-budget fiscal policy what the Phelps-Taylor paper did for monetary policy. Baily argues that rational expectations in the sense of Muth, Lucas, Sargent, and others is no bar to the stabilizing power of fiscal policy if we are realistic enough to hypothesize a certain kind of price or wage stickiness-as distinct from indefinite price-wage fixity. In this restoration Baily succeeds brilliantly, maybe misleadingly well.

Being a captious pedant, I would probably warn my student not to take Baily's modeling of investment behavior entirely literally, adding that it may make some sense if we think of working capital like machine tools and unfinished inventories. I would also complain that (as an approximation, at any rate) Baily's inflation equation is derivable from a model with overlapping wage (or price) commitments and that, accordingly, the size of the parameter $\gamma$ will depend on, among other things, the stabilization rule adopted by the fiscal authorities. But, as already implied, I would leave the student with no doubt as to my admiration for Baily's analysis and clear exposition.

Still, I am afraid that my student, if a skeptical college senior, would return with some searching questions. Where did Baily get the presupposition that macropolicy, either fiscal or monetary, stabilizes any better in the post-Keynes years than it did in the bad old days from 1900 (or 1914) to 1945 ? Was it true, for example, that when the country entered World 
War I the government was less ready to cut back civilian government expenditures and to step up tax rates than it was when we entered Vietnam? I would have to say that I don't know; the student has a point.

Thus encouraged, the student might also venture that Baily gives too rosy and undifferentiated a picture of the stabilizing capacities of balanced-budget fiscal policy-in a monetarist milieu, at any rate. Can we really rescue the economy from disturbances like the oil shock or some sag in the profitability of investment? Within a year or two? And if employment can eventually be propped up again, might not the fiscal medicine gradually lose its effectiveness, and even aggravate the patient's condition in the long run?

These worries are very much in the air these days. Some recent work of my own (on a two-country model of dynamic equilibrium) shows that a balanced-budget fiscal stimulus, though it will increase employment in the short run, may well leave employment lower in the long run than it would have been without that stimulus. By slowing capital formation and real-wage growth, the stimulus drives up the price level and erodes the real value of cash balances; a net tendency toward lower employment seems to be a possible outcome. In that case, if money wages do not perform the necessary downward adjustment, owing perhaps to the expectation of a continuing full-employment policy, monetary policy becomes the only remaining remedy.

My reaction, then, is that Baily has made a good case for keeping balanced-budget expenditure policy in the kit of anticyclical tools, at least in a monetarist world. But I suspect that by focusing on disturbances to consumer demand, where such fiscal policy is at its greatest advantage, Baily may have strengthened what are quite possibly false hopes about the general utility of the balanced-budget instrument.

Benjamin M. Friedman: Martin Baily's interesting paper adds, at both the empirical and the analytical levels, to our efforts to understand the difficult subject of the effects of stabilization policy in a world in which economic behavior depends fundamentally upon expectations about economic behavior. At the empirical level Baily offers evidence that, during the postwar period, businessmen and investors have changed the way in which they form expectations from observing economic developments; and he argues that these changes reflect evolving perceptions of the role of 
government policy in maintaining economic stability. At the analytical level, Baily offers a framework in which correct, or "rational," expectations of monetary and fiscal policy not only do not nullify the intended influence of these policies (as is the case in some models) but even reinforce their effect on the economy's stability.

I will focus first on the overall subject of expectations and the efficacy of policy, and comment briefly on the nature of Baily's analytical model. I will then turn to his empirical work, and comment on the inferences to be drawn about these current controversies over the macroeconomic implications of expectations.

Although Baily motivates this work by referring to the recent literature of "rational" expectations, there are in fact two competing expectations hypotheses in his paper. I think the distinction between them is even more important than his paper suggests. Both hypotheses imply a growing awareness of government policy and its effects on the part of private economic decisionmakers, as is consistent with their observing and learning from the pattern of developments in monetary and fiscal policy since World War II. Beyond that similarity, however, the two hypotheses diverge sharply. In particular, they have precisely opposite implications for the effectiveness of economic stabilization policy.

The first hypothesis is the familiar recent "rational expectations" view: here, as a consequence of certain specifications of economic behavior, the power of monetary policy to influence real variables depends crucially on the ability to surprise private decisionmakers, and monetary policy actions that are anticipated have no real consequences. (Oddly enough, the popular conception of this literature credits fiscal policy, too, with efficacyonly-by-surprise, although, as Ray Fair has recently reminded us, there is no persuasive theoretical case for doing so.) According to this hypothesis, the postwar period of activist stabilization policy should have fooled people at first. As they learned about the new policy approaches and how they worked, however, they should then have changed their behavior in ways that would have offset the stabilizing influence of these policies.

Following Baily's analogy, we may call the second hypothesis the "FDIC effect": here the public's knowledge of the presence of stabilizing monetary and fiscal policy leads to expectations of a more stable economic environment, and these expectations in turn lead to stability-enhancing economic behavior by the private sector. The implication of this alterna- 
tive hypothesis is that, as people learned about the postwar activist stabilization policy, they should have changed their behavior in ways that would have promoted stability.

Two aspects of the analytical approach to these issues merit comment. The first is the curious current vocabulary of this subject, according to which the first hypothesis asserts that people form their expectations "rationally" while the second hypothesis, by process of elimination, asserts the formation of "irrational" expectations. Indeed, some contributors to the recent "rational expectations" literature-for example, Robert Lucas in a recent reply in the American Economic Review-have actually used the word "irrational" to refer to the class of hypotheses consisting of all alternatives to the idea that people form expectations "rationally" in the sense of John Muth's now famous Econometrica paper.

This usage is unfortunate because Muth's conception of "rational" expectations includes not just the presumably unobjectionable idea that people fully exploit whatever information they have but also a more debatable - and, in principle, empirically testable_assumption about how complete that information is. In particular, according to Muth's notion of "rational" expectations as applied in the recent literature, people's subjective expectations of outcomes are identical to the corresponding objective expectations conditional on the process generating those outcomes. In other words, Muth's idea is that people form their expectations "as if" they know the "true" model of the economy. To label as "irrationality" the alternative notion that people exploit fully all the information that they have, but nevertheless do not know the "true" model, seems highly misleading.

The second aspect of "rational expectations" models deserves special attention in the context of Baily's competing "FDIC" hypothesis. The method of solution of "rational expectations" models always requires a terminal condition that, in effect, rules out self-fulfilling expectations. In other words, all such models presume a condition that guarantees that there exists only one set of expectations that can be self-fulfilling in a stable equilibrium. Simply thinking in a different way, with no independent basis for it in fact, does not make new things happen. In "rational expectations" models in which monetary policy is neutral, therefore, changing the policy cannot change the one solution of the model that is consistent with self-fulfilling expectations. Robert Shiller has called attention to the fact that this terminal (or transversality) condition is more significant 
than its usual offhand treatment suggests; and John Taylor and Olivier Blanchard have also questioned the conditions required for a unique "rational expectations" equilibrium.

The relevance of this point here is that Baily's "FDIC" hypothesis seems to suggest that more than one set of expectations can be selffulfilling. This idea per se is not new. Milton Friedman and Anna Schwartz, among many others, suggested it with respect to deposit insurance itself years ago. In that application, however, there is no explicit conflict with the usual requirements of a "rational expectations" model, since bank failure (the excluded possibility) does not constitute a stableequilibrium outcome. The application of this idea to macroeconomic stabilization policy-which Keynes suggested in his remarks in the General Theory on the "state of long-term expectations"--seems again to suggest multiple stable paths to go along with different policies. There is a contrast here, however. Unlike the original FDIC example, Baily's model does use the familiar terminal condition and therefore does have a unique stableequilibrium solution corresponding to each policy. Nevertheless, since Baily's model does not have some of the special elements that make monetary policy neutral under "rational" expectations-in particular, Robert Lucas' only-surprises-matter aggregate supply function-solutions corresponding to different policies are different. The source of their differences, however, is the nonneutrality of the underlying model, and not simply self-fulfilling expectations.

Baily's empirical work demonstrates changes since 1948 in the employment, inventory, and investment responses by firms to observed fluctuations in output. These responses presumably depend, at least in part, on how firms use observed output to forecast future output. Baily interprets his results as showing that these responses have changed in the direction consistent with the "FDIC" hypothesis and inconsistent with the "rational expectations" hypothesis. For example, the employment response of the private nonfarm economy to a sustained 1 percent movement in output has fallen from 1 percent on employment for 1 percent on output in the 1948-61 period to only 0.7 percent or 0.8 percent for 1 percent more recently. Baily notes the stabilizing implications of these results, interpreting them without reference to any excluded variables, but then suggests that the less-than-proportional response to the distributed lag on past output in the later periods means that people are now using information other than observations of past output to form their expectations of future out- 
put-thereby implicitly suggesting that other relevant variables have been excluded from the regressions. This interpretation somewhat clouds the implications of the results, however, since the omitted variables could be concealing additional signs of instability.

I want to suggest an alternative interpretation of Baily's employmentresponse results that sharpens their implications supporting the "FDIC" hypothesis and controverting the "rational expectations" hypothesis. Here I refer first to the results in his table 2 . These regressions relate the logarithm of employment to a constant, a time trend, and a distributed lag on the logarithm of output. It is easiest to conceptualize these expressions as equating the logarithm of employment to the logarithm of expected output plus the logarithm of the desired labor-output ratio. The constant term and time trend on the right-hand side together serve two purposes, not only enabling the desired labor-output ratio to decline exponentially but also permitting the inclusion of an exponential growth trend in the underlying expectation of output.

The approximately unit sum for the lag weights in the distributed lag on output in the regression for 1948-61 indicates that, apart from the time trend, people forecast output as a process that was borderline stationary-nonstationary. In other words, any deviation of output from trend, once maintained for the five-quarter length of the distributed lag, was expected to persist indefinitely. An alternative rendering in logarithmic first-difference terms, which allows for the serial-correlation correction also being approximately unity, implies that any real growth rate that persisted for five quarters became the growth rate people expected for the future. This willingness to accept any recent real growth experience as indicative of prospects suggests that people had little confidence in the ability or willingness of policy to guide the economy.

By contrast, in each of the regressions for later time periods the sum of the weights in the distributed lag on output is well below unity. Instead of either Baily's suggested interpretation that other variables (excluded from the equation) determined the expectations of output, or Baily's noted but rejected interpretation of a less-than-proportional short-run adjustment of employment to expected output, I suggest the following: Firms continued to adjust employment approximately in proportion with expected output, and they continued to form their expectations of output growth by looking at recent output fluctuations. Instead of assuming that output growth would continue to follow the recent experience, however, they forecast this 
growth as a stationary process-that is, as a process that returns over time to a normal level, in this case a positive level promoted by policy. One characteristic of a stationary autoregressive process is that the lag weights sum to less than unity, and Baily's three employment-response regressions for later time periods all have lag-weight sums that are significantly less than unity at the 1 percent level.

A second distinction between stationary and borderline stationarynonstationary forecasting schemes can serve as a check on this interpretation. Whereas a stationary-nonstationary process in this context usually has no constant term, a strictly stationary process does have a constant; in the case of real growth, that constant is again presumably positive. Hence the switch from a borderline stationary-nonstationary forecasting scheme for output in the early years to a stationary scheme later on should imply not only a fall to below unity for the sum of the equation's distributed-lag weights but also an increase for the equation's intercept, which now incorporates two time trends and the constant element of the outputexpectations process. Baily's table 2 shows that in the three regressions for later periods the intercept is indeed greater (apparently significantly so) than in the 1948-61 regression.

Baily's employment-response results based on monthly data for the manufacturing sector, shown in his table 3 , are also consistent with the same interpretation that sharpens their support of the "FDIC" hypothesis. The sum of the distributed-lag weights is again close to unity in the regression for 1949-61 but significantly less than unity at the 1 percent level in each of the three regressions for later time periods, and the intercept in two of these three regressions appears to be significantly greater than that in the 1949-61 regression.

\section{General Discussion}

Several of the discussants pointed out that Baily's hypothesis that government policy had changed behavior in the private sector was not the only explanation consistent with the statistical evidence of structural change in private-sector responses that he had presented. R. A. Gordon mentioned several competing hypotheses to explain smaller fluctuations in output and employment: the increased share of services in total output, pressure from unions to stabilize employment, the increasing importance 
of overhead labor, and the spread of scientific techniques for inventory management. Charles Holt pointed out that inventory and employment decisions are commonly made by lower-level employees who are unlikely to be responsive to changes in government policy or even to national economic developments. They are responsive, instead, to company data, which suggests that structural changes may have arisen from the development of operations research and computers rather than from improved government policymaking.

Holt also noted that higher costs of employment fluctuations, such as supplementary unemployment benefits offered by some firms, could also help explain reduced volatility in output and employment. John Kareken warned, however, that such institutional changes could have been made precisely because fluctuations were expected to be smaller, thus making them an effect rather than a cause of reduced volatility. Christopher Sims pointed out that the growing relative size of the government sector could contribute to greater stability in private output even if stabilization policy itself were not conducted more successfully. Saul Hymans supported Baily's interpretation, noting that although the statistical results themselves might be consistent with numerous hypotheses, he was convinced by Baily's integration of the statistical evidence with his analysis of the institutional environment.

Robert Hall and George von Furstenberg questioned whether government policy had in fact become increasingly stabilizing over the postwar period. Hall said that a cursory glance at the data on the money stock and real government expenditure did not support this proposition and von Furstenberg cited studies by Friedlaender and by Blinder and Goldfeld in which the lagged effects of fiscal policy had been found to be random. However, George Perry noted, around recessions, neither fiscal nor monetary policy had been random. Except in the post-Korean reconversion quarters, both types of policy turned expansionary by the time of cyclical troughs, which was precisely the behavior that would allay fears of a downward spiral in the economy. Baily then pointed out that there was no claim that stabilization policy increased uniformly in effectiveness over the postwar period. The main hypothesis relevant to the empirical analysis was that, by comparison with the years up to 1946, postwar business cycles were moderated and output was kept fairly close to potential output. This change was not anticipated, but was learned through the experience of a few postwar fluctuations. The general climate of opinion attrib- 
uted the change in part to the combined effects of monetary and fiscal policy. The discussion turned to whether Baily's analysis depended on stabilization policy having become more successful. Holt supported Baily's general contention that, in principle, it did not: if postwar economics textbooks and the writings of journalists had taught that fiscal policy stabilizes the economy, people's behavior could change regardless of whether policy, in practice, succeeded.

Hall and Sims suggested that Baily examine the stochastic behavior of output. In particular, for Baily's interpretation of the period, if policymakers reduced the variance of output, he should expect to find that the serial correlation of output was reduced - the path of output was less smooth. It is as a consequence of this lower serial correlation that Baily should expect private decisionmakers to respond less than before to observed shocks in output. Sims noted further that an alternative adjustment could take place: if policymakers tried to smooth output rather than merely reduce its variance, private decisionmakers would be induced to respond more rather than less, knowing that shocks would persist more. 